\title{
Warum «Twitter» kein Medium im Sinne des Strafrechts ist
}

\author{
Matthias Schwaibold *
}

Ein Einzelrichter am Bezirksgericht Zürich sprach einen Angeklagten vom Vorwurf der Ehrverletzung frei, weil die blosse Weiterverbreitung eines «Tweets» - also der «Retweet»-der Bestimmung von Art. 28 StGB unterfalle. Der nachfolgende Beitrag unterzieht die Anwendung des Medienprivilegs aufs Twitter einer kritischen Prüfung.

I. Einleitung 114

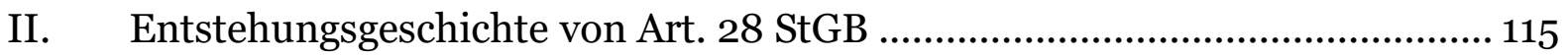

III. Zum Begriff des Mediums ....................................................................... 116

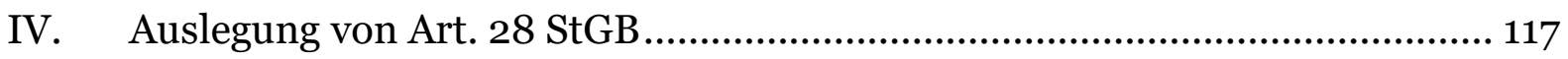

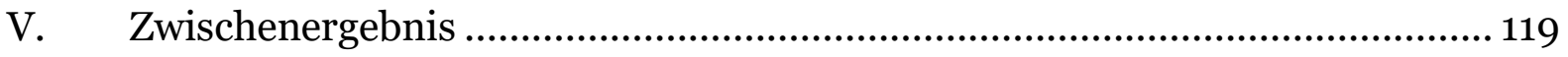

VI. Erwägungen des Bezirksgerichts............................................................ 120

VII. Massenkommunikation = Massenmedium? ................................................124

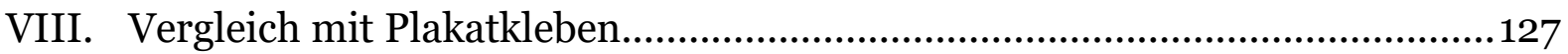

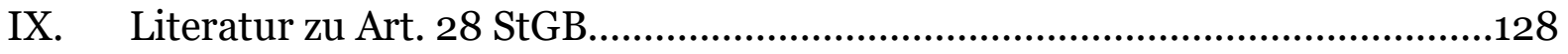

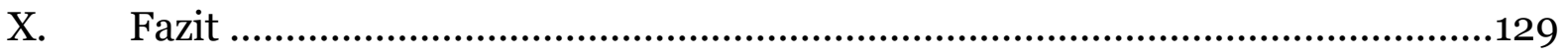

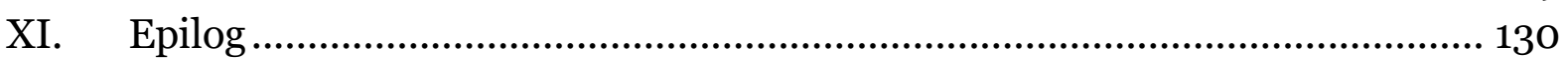

Anhang: Urteil des Beziksgerichts Zürich vom 26. Januar 2016................... 131

Zitiervorschlag: Matthias Schwaibold, Warum «Twitter» kein Medium im Sinne des Strafrechts ist, in: sui-generis 2017, S. 113

URL: $\quad$ sui-generis.ch/39

DOI: $\quad$ https://doi.org/10.21257/sg.39

* Dr. Matthias Schwaibold, Rechtsanwalt in Zürich, Lehrbeauftragter für Medienrecht an der Universität St. Gallen

Ich danke RA lic.iur. Alexandre Reil, Sedlex Avocats Lausanne, und BLaw Luka Schadegg, redaktioneller Mitarbeiter von sui generis, für die freundliche Hilfe bei der Beschaffung der nachfolgend erwähnten Literatur. Weiter danke ich den Professoren Marc Thommen und Daniel Hürlimann sowie Herrn MLaw Luca Ranzoni für weiterführende Hinweise und kritische Anmerkungen zu meinem Entwurf; sie sind in der vorliegenden Fassung unausgewiesen teils übernommen, teils verworfen, aber jedenfalls aufgegriffen worden. 


\section{Einleitung}

1 Spätestens seitdem der derzeitige amerikanische Präsident zeigt, dass man statt mit einer Mannschaft von kompetenten Leuten genauso gut via «Twitter» regieren kann, hat sich das «soziale Netzwerk» endgültig als kommunikativer Faktor in der gegenwärtigen Medienwelt etabliert. Es dürfte heute kaum noch wichtige Politiker im In- und im Ausland geben, die nicht einen «Twitter Account» haben und über diesen Wähler und Nichtwähler zu erreichen suchen oder sich Gehör verschaffen. Die Reduktion der Komplexität auf 140 Zeichen wird schwerlich dazu beitragen, dass das Weltbild von «Twitterern» und «Followern» sich durch übermässige Differenziertheit auszeichnen wird - so viel Kulturpessimismus muss in der Einleitung einer juristischen Abhandlung erlaubt bleiben. Schon lange vor Trumps Wahl die so wenig wie seine Politik Gegenstand der nachfolgenden Überlegungen ist hatte das Bezirksgericht Zürich (Einzelrichter) wegen eines «Tweets» (genauer: eines «Retweets») ein bemerkenswertes Strafurteil gefällt; obwohl nicht rechtskräftig, wurde es in den «Blättern für Zürcherische Rechtsprechung» publiziert. Relativ schnell hat Peter Studer darauf in einer kurzen Besprechung hingewiesen, erst vor kurzem erschien eine eingehende und durchaus kritische Würdigung durch Christian Schwarzenegger ${ }^{2}$.

Urteil des Zürcher Obergerichts vom 26. Januar 2016, in: ZR 115/2016, S. 101-113.

Peter Studer, Retweet-Urteil: Journalist durch Strafrechts-Richter wegen (zivilrechtlicher) Persönlichkeitsverletzung verurteilt, Medialex 2016, 127 ff.; Christian Schwarzenegger, Twibel «Tweets» und «Retweets» mit ehrenrührigem Inhalt aus strafrechtlicher Sicht, in: Daniel Jositsch/Christian Schwarzenegger/Wolfgang Wohlers (Hrsg.), Festschrift für Andreas Donatsch, Zürich 2017, S. 217-231 (zit. Twibel). Während
2 Worum ging es im Ausgangsfall? Y, der im weiteren Verfahren im Gegensatz zu X unbekannt und unbehelligt blieb, verfasste einen Tweet über $Z$, wobei lediglich die dem $\mathrm{Z}$ dabei zugedachte Namensgebung in der Folge eine Rolle spielt und auf die ich erst am Schluss zu sprechen komme. $\mathrm{X}$ erhielt als «Follower» des $\mathrm{Y}$ diesen Tweet und verbreitete ihn seinerseits kommentarlos als «Retweet». Z stellte Strafantrag gegen $\mathrm{X}$ wegen Ehrverletzung. Nach einem hier nicht näher interessierenden Zwischenspiel zum Thema Wahrung der Antragsfrist erhob die Staatsanwaltschaft Anklage, offenbar wegen übler Nachrede und Verleumdung. Das Einzelgericht sprach X vom Vorwurf der üblen Nachrede frei. Allerdings ordnete es gestützt auf Art. $28 \mathrm{ff}$. ZGB an, dass X in einem Tweet zu berichten habe, dass die streitgegenständliche Äusserung zwar nicht strafbar, aber persönlichkeitsverletzend sei.

3 Bevor das Zürcher Obergericht über das vom Privatkläger und der Staatsanwaltschaft eingelegte Rechtsmittel entscheiden konnte, schlossen die Parteien allerdings einen Vergleich; der beinhaltete auch den Rückzug des Strafantrags und führte damit zum Wegfall des angefochtenen, erstinstanzlichen Urteils3. Dieses ist sozusagen nur noch als literarisches Produkt vorhanden, aber strafrechtlich inexistent. Das soll nicht hindern, die strafrechtlichen Überlegungen, die zum Freispruch des Angeklagten führten, kritisch zu hinterfragen, zumal angesichts

Studer das Urteil, soweit man seinem Beitrag eine Wertung entnehmen kann, es im hier interessierenden Bereich positiv zu sehen scheint, hebt Schwarzenegger zurecht dessen Schwächen hervor.

$3 \quad$ Studer (Fn. 2), S. 130, Nachtrag der Redaktion. 
der vorstehend erwähnten Bedeutung, die «Twitter» erlangt hat, es auf der Hand liegt, dass der nächste Straffall mit einer vergleichbaren Konstellation nicht jahrelang auf sich warten lassen wird4. Aber in einem solchen Verfahren wird man als Richter sich nach Meinung des Verfassers (früher selbst nebenamtlicher Richter) jedenfalls eine andere Begründung für einen Freispruch suchen müssen: So erfrischend, modern, ja unorthodox der Zugriff des Zürcher Einzelrichters auf das Medium «Twitter» erfolgte, so falsch ist ihm die Subsumption geraten.

\section{Entstehungsgeschichte von Art. 28 StGB}

4 Es gibt keine Legaldefinition der Medien in Art. 28 StGB. Man muss sich also diesem Begriff annähern, und eine solche Annäherung kann nicht ohne den Blick auf den Zweck der Regelung, damit wiederum auf ihre Geschichte erfolgen.

5 Als das StGB 1942 in Kraft trat, gab es nur gerade zwei Medien: Die gedruckten (namentlich Zeitungen und Zeitschriften) und das Radio. Film und Schallplatte waren keine Medien, auf die man im strafrechtlichen Zusammenhang des - damaligen - Art. 27 StGB gekommen wäre, sowenig wie damals und seither das Telefon. Zudem war dieser Art. 27 StGB auf Publikationen, die «durch das Mittel der Druckerpresse» hergestellt worden waren, beschränkt; er galt also gerade nicht für das Radio, dafür aber auch für nicht-

4 Die zahlreichen Entscheide zum «Kristallnachttweet» sind deshalb vorliegend ohne Bedeutung, weil der Verstoss gegen Art. 261 ${ }^{\text {bis }}$ StGB (Rassendiskriminierung) gerade vom Anwendungsbereich des Art. 28 StGB ausgenommen ist; dazu kritisch Schwarzenegger, Twibel (Fn. 2), S. 226 mit Fn. 41. periodische Druckerzeugnisse wie Bücher. Daraus folgt: Nicht alles, was wir heute als «Medien» betrachten, und gerade auch nicht alles, was sicher schon damals «Medien» waren - eben gerade das Radio! -, unterfiel der Sonderregelung, sondern diese war auf eine bestimmte «Herstellungsart» von Medien beschränkt. Darauf ist zurückzukommen.

6 Die Revision zum 1. April $1998^{5}$ dehnte den Anwendungsbereich des Art. 27 StGB auf «Medien» ganz allgemein aus; mit dem Abschied von der «Druckerpresse» erfasst werden sollten damit insbesondere neben dem Radio auch das längst etablierte Fernsehen, aber auch die elektronischen Medien; allerdings war auch damals nicht absehbar, was 20 Jahre später alles unter dem - in jener Zeit gerade bekannt gewordenen - «Internet» segelt. Klarerweise nicht erfasst vom neuen Medienbegriff war aber weiterhin das Telefon. Daraus folgt: Nicht alles, was der Kommunikation dient, ist ein Medium im Sinne des Strafrechts. Weshalb auch die inzwischen vollkommen in der Normalität angekommene elektronische Individualkommunikation wie namentlich E-Mail nicht unter den Medienbegriff des einschlägigen Strafrechtsartikels fällt.

7 Besonderes Kennzeichen, ja eigentlicher Inhalt der Bestimmung von Art. 27 StGB in der ursprünglichen Fassung von 1937/1942 war eine Sonderregelung der Strafbarkeit. Haftbar für eine in den gedruckten - Medien erfolgende, und

5 Bundesgesetz vom 10. Oktober 1997 über das Schweizerische Strafgesetzbuch (StGB, SR 311.0); Botschaft über die Änderung des Schweizerischen Strafgesetzbuches und des Militärstrafgesetzes (Medienstraf- und Verfahrensrecht) vom 17. Juni 1996, (BBl 1996 IV 525) S. 525 ff. 
sich in der Veröffentlichung erschöpfende Straftat war allein deren Autor. Nur für den Fall, dass er unbekannt bliebe oder in der Schweiz nicht vor Gericht gestellt werden könnte, war an seiner Stelle der Redaktor, der Verleger oder der Drucker verantwortlich, wobei auch hier noch zwischen periodischen und nichtperiodischen Publikationen sowie zwischen Artikeln und Anzeigen unterschieden wurde. Diese Kaskadenhaftung, welche die Bestrafung anderer anstelle des Autors erlaubte ${ }^{6}$, wurde 1998 durch die ausdrückliche Strafbarkeit der Nichtverhinderung einer strafbaren Publikation ersetzt?

\section{Zum Begriff des Mediums}

8 Für die Anwendung ist also zu fragen, was «Medium» im Sinne der (zum 1. Januar 2007 lediglich formell ${ }^{8}$ ) revidierten, heutigen Bestimmung des Art. 28 StGB ist. Dabei kann «Medium» nicht einfach sein, was heute als Medium bezeichnet wird: Die sogenannt «sozialen Medien» (eine doch eher misslungene Verdeutschung der «social media») können jedenfalls nicht für sich in Anspruch nehmen, voraussetzungslos ein Medium im Sinne der fraglichen Bestimmung zu sein. Auch der früher allenfalls brauchbare Begriff der «Massenmedien» kann nicht helfen: Denn die technische Entwicklung hat die Abgrenzung der Individual- von der Massenkommunikation weitgehend verwischt. Allerdings kann

$6 \overline{\text { Vgl. zur ursprünglichen Gesetzesfassung z.B. Paul }}$ Logoz, Commentaire du Code Pénal Suisse, partie générale (Art. 1 à 110), Neuchâtel/Paris 1939, S. 111-118 (n.b.: Dieses Buch erschien vor Inkrafttreten des StGB).

7 Art. $322^{\text {bis }}$ StGB.

8 Schweizerisches Strafgesetzbuch und Militärstrafgesetz, Änderungen vom 24. März 2006, (AS 2006 3459). nicht einfach jede Kommunikation der Sonderregelung unterfallen kann, weil sie sonst gar keinen abgrenzbaren Anwendungsbereich hätte, also eine Gleichsetzung von «Kommunikation» mit «Medium» darf sicher nicht erfolgen. Ebenso wenig darf man «Veröffentlichung» und «Medium» gleichsetzen, denn Art. 28 StGB handelt ja von der «Veröffentlichung in einem Medium», setzt also auch hier eine Unterscheidung voraus. Für den Medienbegriff muss also zwischen Verbreitung und Inhalt nach einer Beziehung gesucht werden: Nicht jede an einen unbestimmten (oder zwar bestimmten, aber zahlenmässig [sehr] grossen) Empfängerbereich gerichtete Kommunikation kann Medium sein, umgekehrt kann die blosse Verbreitungsmöglichkeit durch Dritte nicht entscheidend sein, weil es nämlich bei der fraglichen Bestimmung gerade - wenn auch nicht ausschliesslich - um die Strafbarkeit dieser Dritten geht, mithin um die Frage, ob sie «Täter» oder «Teilnehmer» sind, also einer Strafdrohung unterfallen, oder eben nicht. Die Privilegierung bestimmter Dritter hing und hängt also nicht davon $a b$, ob sie Verbreiter überhaupt waren, sondern griff und greift heute noch dann und deshalb, weil sie Verbreiter eines Mediums waren; Medium, Verbreitung und Strafbarkeit bzw. Ausschluss derselben stehen in einem durchaus nicht unkomplizierten Verhältnis zueinander.

9 Soweit ersichtlich, hat sich zuletzt Christian Schwarzenegger in zwei Aufsätzen mit der durch die technische Entwicklung unvermeidlicherweise aufgeworfenen Frage befasst, was Medium im Sinne 
des Strafrechts sei9. Seiner Problemanalyse und der beidesmal entschieden vorgetragenen Feststellung, dass Rechtsunsicherheit herrscht und gesetzgeberischer Handlungsbedarf besteht, ist vorbehaltlos zuzustimmen. Während in seinem ersten Artikel «Twitter» nicht vorkommt, ist der zweite ganz ausdrücklich diesem Thema gewidmet.

\section{Auslegung von Art. 28 StGB}

10 Die Annäherung an den Begriff des Mediums in Art. 28 StGB kann bzw. muss von drei Seiten her erfolgen:

11 Zum einen mit Blick auf den Quellenschutz des Art. 28a StGB, der auf «periodisch erscheinende Medien» eingeschränkt ist. Davon ausgehend, dass das Wort «Medien» eine halbwegs deckungsgleiche Bedeutung in beiden Bestimmungen hat, erlaubt der engere des Art. 28a jedenfalls einen ersten Zugriff auf den weiteren des Art. 28 StGB. Auch für das Bundesgericht stehen die Art. 28 und 28a StGB zumindest in einem $\mathrm{Zu}$ sammenhang ${ }^{10}$, für Stéphane Werly sind sie sogar «intimement liés»11. Der Begriff des «periodisch erscheinenden Mediums» ist auch strafrechtlich deckungsgleich mit dem zivilrechtlichen, also demjenigen des Gegendarstellungsrechts (Art. $28 \mathrm{~g}$ ff. ZGB), und der zivilprozessualen (Art. 266 ZPO). Wesentliche Elemente des «periodisch erscheinenden

$9 \overline{\text { Christian Schwarzenegger (Fn. 2) und schon }}$ fünf Jahre zuvor ders., Der Anwendungsbereich des Medienstrafrechts (Art. 28, 322 $2^{\text {bis }}$ StGB), in: Liber amicorum für Andreas Donatsch, hrsg. von Angela Cavallo et al., Zürich 2012, S.165 ff. (zit. Anwendungsbereich).

10 BGE 136 IV 145, E. 3.2, S. 149 f.

11 Stéphane Werly, in: Robert Roth/Laurent Moreillon, Commentaire Romand, Code pénal I, Basel 2009, Rz 2.
Medium» sind neben seiner «Periodizität» - also der in einigermassen geordneten Zeitintervallen erfolgenden Verbreitung - die redaktionelle Bearbeitung bzw. Aufbereitung der Inhalte und der relativ gleiche Empfängerkreis. Betont man den Prozess der Bearbeitung und vernachlässigt man den Gesichtspunkt der Arbeitsteilung, dann ist auch die von einem «Alleinredaktor» regelmässig publizierte Postille ein solches «periodisch erscheinendes Medium» - hingegen macht die blosse, auch regelmässige, gar tägliche/stündliche Absonderung von Meinungen zu irgendetwas oder über irgendwen deren Gesamtheit nicht ${ }^{12} \mathrm{zu}$ einem «Medium» und die Veröffentlichung nicht $\mathrm{zu}$ einem «fortgesetzten Kontakt mit dem Publikum»13.

12 Von dort hergesehen, fällt es schwer einzusehen, dass das «Medium» des Art. 28 StGB etwas vollkommen anderes als das «periodisch erscheinende Medium» des Art. 28a StGB sein soll. Gewiss schränkt das Merkmal der «Periodizität» den Anwendungsbereich des Art. 28a StGB klar ein - umgekehrt wäre es wohl verkehrt, einfach alles, was nicht «periodisch» ist, bloss deshalb schlechthin als Medium gelten lassen zu wollen. Anders herum: Der Medienbegriff des Art. 28 StGB muss sich am Medienbegriff des Art. 28a StGB orientieren.

13 Die zweite Annäherung kommt vom Zweck der Bestimmung des Art. 28 StGB her: Es ging darum, mit der Beschränkung der Strafbarkeit auf den Autor ei-

$12 \overline{\mathrm{Zu} \text { ergänzen: jedenfalls nicht per se, sondern }}$ höchstens sehr ausnahmsweise und unter besonderen Umständen

13 Franz Zeller, Basler Kommentar, Strafrecht I, 3. Auflage, Basel 2013, Art. 28a N 18. 
nen Beitrag zur freien Meinungsbildung zu leisten. Medienfreiheit war - historisch gesehen - eben zuerst einmal Pressefreiheit; die «Pressfreiheit» des Art. 55 der alten Bundesverfassung von 1874 und «das Mittel der Druckerpresse» des Art. 27 StGB in seiner ersten Fassung von 1937/42 waren eben wesensverwandt ${ }^{14}$. Modern verstandene Pressefreiheit ist zwar «Medienfreiheit», kann aber nicht unbesehen die erhebliche Erweiterung auf alles, was man heute in der Alltagssprache als «Medien» bezeichnet, zur Folge haben. Denn die Medien- und Meinungsfreiheit ist nach völlig herrschender Auffassung nicht einfach «unbeschränkt», sie unterfällt vielmehr den vielfältigen Schranken der Rechtsordnung (namentlich Persönlichkeitsschutz, Strafrecht, Wettbewerbsrecht, Datenschutz, um nur einige Bereiche zu nennen). Auch der blosse Umstand, dass die moderne Technik viele verschiedene «Medien» hervorgebracht hat, erlaubt nicht, vom Medium einfach auf die Anwendbarkeit des Art. 28 StGB zu schliessen: Vom Schnurtelefonapparat, der unsere Sprache über Kupferleitung übermittelte, und anderen Formen analoger Übertragung sind wir schon wieder weg, vielmehr bei digitaler Telefonie, beim Smartphone, WLAN angekommen und allem weiteren, was das «Internet» uns sonst noch alles beschert hat, inklusive seiner eigenen Kinder, wie «Apps». Unter dem Stichwort «Konvergenz» haben sich einst rechtlich und technisch entscheidende Unterschiede in der Informationsübertragung aufgelöst. Also kann auch die Technik allein nicht mehr das

$14 \overline{\operatorname{Logoz}(F n .7) \text {, hält denn auch auf S. } 114 \text { fest, dass }}$ eine Visitenkarte zwar auch ein Druckerzeugnis sei, aber keine Publikation im Sinne dieser Bestimmung. entscheidende Kriterium sein. Das Medium muss, um eines zu sein und der Sonderregelung zu unterfallen, der Meinungsfreiheit und Meinungsbildung seiner Empfänger dienen ${ }^{15}$, es kann sich deshalb auch nicht in der blossen Freiheit des Absenders/Verfassers erschöpfen ${ }^{16}$.

14 Führen wir uns schliesslich eine dritte Überlegung vor Augen: Wenn A am Stammtisch einen Dritten beleidigt, ist er im Rahmen der einschlägigen Bestimmungen strafbar; wenn B die von A geäusserte Beleidigung verbreitet, ist er seinerseits strafbar, und das gilt auch dann, wenn die Verbreitung in einem (periodisch erscheinenden) Medium erfolgt; daran ändert auch nichts, dass B als Quelle den A angibt und vielleicht sogar vollkommen korrekt zitiert («keine Flucht ins Zitat»). Dann ist zu fragen: Soll die über «Twitter» verbreitete Beleidung anderen Regeln unterfallen als die am Stammtisch geäusserte? Soll tatsächlich derjenige, der eine über Twitter verbreitete Beleidigung über Twitter weiterverbreitet, also der «Retweeter» wie der im vorliegenden Fall Angeklagte X, gegenüber demjenigen, der sie mündlich verbreitet, anders behandelt werden? Soll die zuerst am Stammtisch geäusserte Beleidigung, wenn sie über Twitter weiterverbreitet wird, anders betrachtet werden als wenn sie mündlich verbreitet wird? Darf es mithin auf den Verbreitungsweg bzw. Verbreitungskanal ankommen?

15 Ähnlich Schwarzenegger, Anwendungsbereich (Fn. 9), S. 169-172.

16 Welcher Gesichtspunkt in der vorliegend konsultierten Lehre nicht vertieft worden zu sein scheint. 


\section{Zwischenergebnis}

15 Die Frage ist zu verneinen, und damit sei zugleich der Versuch einer - wenn auch unvollständigen und insbesondere «negativen» - Umschreibung des Medienbegriffs gemäss Art. 28 StGB unternommen: Medium ist erstens nur, was der freien Meinungsäusserung dient; Beleidigungen gehören in aller Regel gerade nicht dazu. Medium ist weiter, was nicht in erster Linie individuelle Äusserung, sondern «aufbereitete», also redaktionell-journalistisch bearbeitete Information ist; dass Journalisten in Zeitungen/ Zeitschriften/Onlinemedien auch subjektive Meinungen («Kommentare») verbreiten, ändert nichts daran, dass sie sich in Ausübung einer (haupt)beruflichen Tätigkeit äussern, die auf Informationsvermittlung und Meinungsbildung hinzielt. Das unterscheidet diese Form der Kommunikation von der Individualkommunikation des (Telefon-) Gesprächs, der E-Mail oder der Skype-Unterhaltung, das unterscheidet sie aber auch von der Logorrhoe derjenigen, die sich überall und jederzeit auf irgendwelchen Kanälen zu allem äussern. Bloss deshalb, weil der (bei üblicher Individualkommunikation sehr beschränkte) Empfängerkreis technisch erweitert wird, wird der Verbreitungskanal nicht plötzlich zum Medium: Nicht inhaltlich, sondern nur technisch unterscheidet sich ein Tweet von einem Facebook-Posting oder einer sonstigen, individuellen Verlautbarung. Der Tweet ist nichts anderes als die Mitteilung eines in der Regel bekannten Absenders an einen (weitgehend) undefinierten und von ihm auch nicht real beschränkbaren Empfängerkreis. Der Tweet ist als (spontane oder wohlüberlegte) Kurzmitteilung weder einem Artikel oder Kommentar gleichzusetzen noch ist Twitter selbst ein redaktionelles Gefäss, das einen (wie auch immer) Verantwortlichen hätte: Kennzeichnend ist ja gerade, dass jeder alles verbreiten kann, sofern er nur ein Twitter-Account hat und sich auf 140 Zeichen beschränkt. Tweet und Retweet sind also nichts Weiteres als (relativ neue) technische Verbreitungsmöglichkeiten einer Individualäusserung, aber diese sind weder im Einzelnen noch insgesamt ein Medium noch können sie überhaupt zu einem solchen werden; bloss dadurch, dass viele gleichzeitig Vieles und Verschiedenes einander mitteilen, entsteht kein Medium. Der grosse Empfängerkreis und die Möglichkeit der (tendenziell unbegrenzten) Verbreitung macht es auch nicht zu einem Massenmedium im Sinne des Art. 28 StGB, sowenig wie es Facebook, Instagram oder weitere Plattformen bzw. «social media» sind ${ }^{17}$.

16 Aus dem Medienbegriff der lex lata leite ich deshalb auch ab, dass die von einer (seriösen) Medienunternehmung verbreiteten Tweets dem Medienstrafrecht unterfallen und es insoweit auch durchaus auf den Absender bzw. Verfasser ankommt. Hingegen ist meiner Meinung nach im vorliegenden Zusammenhang nicht $\mathrm{zu}$ unterscheiden zwischen dem Tweet - also der Ursprungsmeldung -, dem Retweet - also der Weiterverbreitung durch einen Empfänger des Tweets (oder Retweets) -, und Twitter als der technischen Plattform. Sowenig wie das Internet selbst ein Medium ist, ${ }^{18}$ sowenig kann Twitter eines sein.

17 Dass Tweet und Retweet unbezweifelbar «Veröffentlichung» sind, ist für die Frage des Medienbegriffs nicht entscheidend; gl.M. Schwarzenegger, Twibel (Fn. 2), S. 227.

18 So ausdrücklich Schwarzenegger, Anwendungsbereich (Fn. 9), S. 174. 
17 Denn Twitter ist nur, aber immerhin ein technischer Verbreitungskanal für Mitteilungen an eine - wie auch immer beschränkte oder gar unbeschränkte Öffentlichkeit, aber deshalb kein Medium im Sinne des Art. 28 StGB, selbstredend erst recht keines im Sinne von Art. 28a StGB. Der Medienbegriff darf gemäss Zeller nicht durch die Erfassung von Formen direkter Kommunikation «strapaziert» werden ${ }^{19}$; ich meine sogar, dass er als ein Gegenbegriff zu direkter Kommunikation verstanden werden muss und man sich bei der Unterscheidung weiterhin an alle dem orientieren kann, was man früher - in einer insoweit bezüglich «Medienvielfalt» viel ärmeren Zeit - mit der gedruckten Presse verbunden hat ${ }^{20}$.

\section{Erwägungen des Bezirksgerichts}

18 Die vorstehenden Überlegungen sind denjenigen im Urteil gegenüberzustellen, das zum Schluss kam, Twitter sei ein Medium im Sinne des Art. 28 StGB. Dabei fällt auf, dass zwar praktisch alle der richterlichen Argumente sich in irgendeiner Form in der massgebenden Kommentierung von Franz Zeller im Basler Kommentar zu Art. 28 StGB finden ${ }^{21}$,

19 Zeller (Fn. 13), Art. $28 \mathrm{~N} 44$.

20 Schwarzenegger, Anwendungsbereich (Fn. 9), hält auf S. 174 zutreffend fest, dass niemand auf die Idee käme, den für die Verteilung gedruckter Zeitungen verwendeten Lastwagen als «Medium» zu bezeichnen; wendet man diesen Gedanken, dass jedenfalls das blosse «Transportmittel» nicht mit dem Medium gleichzusetzen ist, auf «Tweets», «Retweets» und «Twitter» an, so scheint mit der Schluss unausweichlich, dass «Twitter» schon, aber nicht allein deshalb, kein Medium ist. In Twibel, verwendet Schwarzenegger (Fn. 2) auf S. 229 das richtige Bild, dass «Twitter» allenfalls die «Wand», nicht aber das «Plakat» sei.

21 Wie Schwarzenengger, Twibel (Fn. 2), auf S. 228 festhält, ist diese Kommentierung neben dem «Plakatentscheid» BGE 128 IV 53 ff. die prak- aber damit ist noch nicht entschieden, dass die Subsumption gelungen ist.

19 Ad Erw. 4.2.1.: Es ist richtig, dass die Gesetzesrevisionen weg von der «Druckerpresse» hin zu Radio und Fernsehen führten, aber nicht auf diese beiden beschränkt waren. Ist bloss deshalb der Medienbegriff unbeschränkt, weil er viele neue Phänomene umfasst? Sicher ist er schon deshalb einzuschränken, weil er Begrenzungsfunktionen hat, weil er sonst nicht geeignet wäre, die Ausnahme von den allgemeinen Bestimmungen über die Teilnahme überhaupt zu bewirken.

20 Ad Erw. 4.2.2.: Das Gericht erwähnt zutreffend die Praxis zur (ursprünglichen) Bestimmung des Art. 27 StGB: Die Kaskadenhaftung führte nicht zu einer Ausdehnung der Strafbarkeit auf jedermann, sondern war auf die nach bzw. «hinter» dem Autor an dessen Stelle im Gesetz benannten Personen beschränkt. Die Kaskadenhaftung bezog sich aber nicht auf die Phase vor der Publikation, sondern erst auf die nach erfolgter Publikation. Und schliesslich hatte man in grosszügiger Erweiterung der im Gesetz genannten «Druckerpresse» auch die Matrize und die Schreibmaschine als «Herstellungsmedium» gelten lassen, solange es darum ging, einen Text herzustellen, zu vervielfältigen und zu verbreiten und sich das strafrechtliche Problem darin erschöpfte. Aber auch mit einer solchen in der Vergangenheit erfolgten Erweiterung ist nicht gesagt, dass heute einfach jede Herstellungs- und Verbreitungsart der Sonderbestimmung unterfällt. Es kommt ja weiterhin nicht allein auf die «Verbreitung» an, sondern dass diese in einem

tisch einzige Quelle, die das Einzelgericht für seine Überlegungen anführt. 
«Medium» erfolgt; das verbietet, wie erwähnt, eine Gleichsetzung und verlangt vielmehr eine Unterscheidung. Deshalb ist aus dem vom Einzelgericht weiter erwähnten «Plakatentscheid» 22 nichts für den Medienbegriff abzuleiten: Das Plakat enthielt die ehrverletzende Mitteilung an die Öffentlichkeit, so dass es keine Verkennung der Sonderregelung darstellte, die Plakatkleber als blosse Verbreiter freizusprechen, hingegen diejenigen, die für den Inhalt verantwortlich waren, zu bestrafen. Wie das Bundesgericht ausführte, ging es auch im revidierten Recht darum, einen Verantwortlichen «au sein de l'entreprise de média» für verantwortlich zu erklären (a.a.O. S. 67 Erw. 5 e.) was erneut belegt, dass als Medium eben ein Unternehmen, eine Organisation verstanden wird und damit nicht der blosse Verbreitungsweg gemeint sein kann. Für den Medienbegriff kommt es deshalb auch auf den Absender/Verfasser an, was den Tweet des quivis ex populo von demjenigen einer seriösen Zeitung bzw. Medienunternehmung unterscheidet. Die "chaîne de production et de diffusion", innerhalb derer gemäss Art. 28 StGB die Strafbarkeit eingeschränkt ist, ausserhalb derer sie aber gegeben sein kann, setzt ausserdem ihre eigene Existenz voraus: Wo Produktion und Verbreitung nicht mehr auseinanderfallen, wo es an einem «pressemässigen Mitwirken» (so die S. 67/68 vom Bundesgericht zitierte Meinung von Hans Schulz von 1982) fehlt, ist auch nicht zu sehen, warum die Sonderregelung gelten sollte.

Ad Erw. 4.2.3.: Das Urteil sagt richtigerweise, dass das Weiterverbreiten ehrenrühriger Meldungen ein eigenständiges

22 BGE 128 IV 53 ff.
Delikt ist (eben selbst Ehrverletzung). Die Ausnahmeregelung des Art. 28 StGB gilt nun aber nicht für jede Verbreitung, sondern eben nur die Verbreitung innerhalb der für das Medium typischen Verbreitungskette. Dabei verkennt das Gericht - durchaus vom Bundesgericht in die Irre geleitet -, dass nicht, jedenfalls nicht zwingend, von einer «Verbreitungskette» auf die Existenz eines Mediums geschlossen werden kann: Denn das ehrenrührige Plakat ist nicht deshalb ein «Medium», weil es tatsächlich verteilt und geklebt wurde, sondern weil es der physische Träger einer gedruckten politischen Botschaft war; für das Plakat typisch ist aber, dass es geklebt werden muss, und zwar an möglichst vielen verschiedenen Stellen, denn als blosser Papierstapel in einem Keller kann es seine Wirkung nicht erzielen, aber spätestens mit dem Ankleben am ersten Laternenpfahl. Ebenso ist das Buch nicht deshalb Medium, weil es früher über Buchhandlungen vertrieben wurde (heute zunehmend über die Verlage selbst bzw. über teils weltweit agierende Verteilunternehmen wie «Amazon»). Erst vom Medium her ist vielmehr die typische Verbreitungskette zu beurteilen - die dazu führt, dass der Plakatkleber so wenig wie der Buchhändler strafrechtlich haftet, was aber im Umkehrschluss auch sagt, dass der Verbreiter ausserhalb der typischen Verbreitungskette strafrechtlich haftet, wie sowohl das Bundesgericht wie das Bezirksgericht erkennen. Mit andern Worten setzt die Beurteilung der Verbreitungskette voraus, dass es sich bei der in Frage stehenden Publikation um ein Medium handelt, man kann also gerade nicht aus der blossen Existenz einer Verbreitungskette auf den Mediencharakter schliessen. 
Ad Erw. 4.3.: In dieser - zentralen - Erwägung gelang der Einzelrichter zum Schluss, Twitter sei ein Medium. Die Argumentationskette hält einer kritischen Überprüfung nicht stand, jedenfalls nicht im Lichte der vorstehend angestellten Überlegungen.

Ad Erw. 4.3.1.: So ist die Bezeichnung als «social media» auf Deutsch oder Englisch gerade kein ausreichender Umstand: Aus dem Sprachgebrauch ableiten zu wollen, dass Veröffentlichungen auf Twitter dem Art. 28 StGB unterfallen, ist eine sowohl strafrechtlich wie sprachtheoretisch unzulässige Ableitung. Denn das esoterisch-spiritistische «Medium» ist sicher keines, das dem Art. 28 StGB unterfällt, sowenig wie blosse «Speichermedien». Und auch die - im Urteil nicht weiter vertiefte - alltagstypische Umschreibung von Twitter als eines «Kurznachrichtendienstes» hilft nicht, denn weder die Wortbestandteile «Kurznachricht» noch gar «Nachrichtendienst» erlauben den Schluss, es handle sich bei Twitter um ein Medium: Auch die SMSbzw. WhatsApp-Meldungen sind Kurznachrichten.

Ad Erw. 4.3.2.: Zurecht weist der Einzelrichter darauf hin, dass es Twitter noch gar nicht gab, als die massgebliche Revision des Art. 28 StGB verabschiedet wurde, und der Gesetzgeber damals vor allem an Radio und Fernsehen dachte. Dass der zum Gesetz gewordene Text nicht ausdrücklich auf Radio und Fernsehen Bezug nahm, sondern das - nach Ansicht des Gerichts «farblose» und «umfassende» - Wort «Medium», hilft allerdings auch nicht weiter: Aus der Absicht, seither wieder untergegangene (Teletext und Videotex) und damals wie heute noch unbekannte Medien der Regelung in gleicher Weise wie die bekannten Medien unterstellen zu können, ohne das Gesetz ändern zu müssen (strafrechtliches Legalitätsprinzip!), folgt nämlich nicht einfach, dass Twitter ein Medium sei. Schon gar nicht kann die Entstehungsgeschichte «eher» dafür sprechen, dass es eines sei als keines: Was zur Zeit der Verabschiedung des Gesetzes noch gar nicht existierte, kann aus logischen Gründen nicht mit Hilfe der «Entstehungsgeschichte» einer Norm beurteilt werden.

25 Ad Erw. 4.3.3.: Das Gericht erwägt zutreffend den gesetzeshistorischen Zusammenhang zwischen der Regelung des Art. 28 in der neuen Fassung und dem Quellenschutz des Art. 28a StGB. Das stärkt die vorstehend unter 4.1. vorgetragene Ansicht, dass man die beiden Bestimmungen, genauer den «Medienbegriff» nicht völlig unabhängig voneinander sehen darf.

26 Unbegründet ist hingegen die weitere Behauptung, ein «Blog» auf einer Website sei mit Twitter vergleichbar: Worin genau die relevante «Gleichheit» oder die «Vergleichbarkeit» besteht, erklärt das Gericht nämlich nicht, die Behauptung erfolgt apodiktisch und hat keinen logischen Zusammenhang mit dem vom Gericht zuvor erwähnten BGE 136 IV 145. Es mag solche eine Vergleichbarkeit oder gar eine Gleichsetzung erlaubenden Elemente geben - aber sie werden nicht ausgeführt, und sie würden auch nichts daran ändern, dass aus anderen Gründen Twitter kein Medium im Sinne des Art. 28 StGB ist. Das Bundesgericht beurteilte im genannten BGE 136 IV 145, S. 150, Erw. 3 Sätze 1 und 2, nämlich das 
Schweizer Fernsehen als periodisch erscheinendes Medium und entschied über den Quellenschutz, nicht aber über die Frage, ob ein Blog-Beitrag seinerseits ein Medium sei. Dies bestätigt nebenbei die oben wiederholt zum Ausdruck gebrachte Auffassung, dass es sehr wohl auf den Absender ankommt, wenn man die Frage nach der Medieneigenschaft zu beantworten hat.

Ad Erw. 4.3.4.: Ebenso unbehelflich ist es, die ratio legis des Art. 28 StGB zu bemühen: Gewiss dient die Beschränkung der Strafbarkeit dem freien Meinungsaustausch - doch damit ist nichts für die Frage gewonnen, ob Twitter ein Medium sei. Denn auch das Telefon und die E-Mail bzw. deren (Geheimnis-) Schutz dienen der Meinungsfreiheit, ohne dass deshalb jede Äusserung über E-Mail oder Telefon straflos wäre. Dass sich der in Frage stehende Tweet auf eine politische Angelegenheit bezog, hat auch nichts damit zu tun, dass deshalb Twitter ein Medium sein müsse: Wie das Gericht erkennt, können über Twitter auch apolitische Banalitäten ausgetauscht werden, also darf man gerade nicht vom konkreten Inhalt des prozessgegenständlichen Tweets auf den Charakter von Twitter als Medium schliessen. Daran ändert schliesslich auch nichts der Hinweis auf die - traurige - politische Realität Chinas, das Twitter weitestgehend unterdrückt: Die Meinungsfreiheit ist in China auch sonst praktisch inexistent, sowenig wie man ernsthaft behaupten kann, das politische System Chinas entspreche hiesigen Vorstellungen von Demokratie. Twitter ist nicht deshalb ein Medium, weil es autokratische Systeme stört. Deren Kennzeichen ist ohnehin, die Kommunikation über Internet entweder zu unterbinden oder durch allerlei Zensurmassnahmen einzuschränken, was bekanntlich schon manch einem, der sich unvorsichtigerweise über Facebook zu religiösen Fragen in orthodox-islamischen Staaten äusserte, zum Verhängnis wurde.

28 Ad Erw. 4.3.5.: Das Gericht wendet sich anschliessend den Missbrauchsgefahren zu, die es richtig sieht. Allerdings ist auch das nur ein Scheinargument: Jedes Medium kann missbraucht werden, die E-Mail gleich wie Radio und Fernsehen oder die Zeitung oder das Telefon oder ein Blog oder eine nur im Internet erscheinende Online-Zeitung. Die vom Einzelrichter zurecht erkannte Problematik, dass sich der Urheber einer Beleidigung hinter einem zuvor selbst produzierten Tweet straflos verstecken könne, wenn der Retweet - wie er meint - straflos sein müsse, ist doch völlig belanglos, wenn es um die Frage geht, ob Twitter ein Medium ist: Diese Frage ist doch zuerst zu beantworten, aber lässt sich so wenig wie in anderen Zusammenhängen erst über die Frage eines möglichen Missbrauchs beantworten. Und mit der richtigen Subsumption - dass Twitter eben gerade kein Medium ist - hätte sich auch die Frage nach dem Missbrauch erledigt.

29 Ad Erw. 4.3.6.: Schliesslich hängt die Frage, ob Twitter ein Medium sei, sicher nicht davon ab, dass es zivilrechtliche Schutzansprüche auch dort gibt, wo strafrechtliche fehlen: Dass der Retweeter nach der lex lata zivilrechtlich haftet, trägt gerade nichts zur allein zu entscheidenden Frage bei, ob Twitter ein Medium sei, denn auch die straflose Ehrverletzung (Entlastungsbeweis!) am Stammtisch schützt den Beleidiger zivil- 
rechtlich nicht, sowenig wie es darauf ankommen kann, ob zivilrechtliche Sanktionen als mindestens so wirksam erscheinen wie strafrechtliche: Dieser Gedanke kann in seiner völligen Abstraktheit niemals ein Argument dafür sein, Twitter als Medium zu erkennen oder gerade nicht. Die Existenz zivilrechtlicher Sanktionsmöglichkeiten ist nämlich schlicht kein Argument dafür, wenn es darum geht, einen Begriff des Strafrechts auszulegen oder - genauer - darüber zu entscheiden, ob ein bestimmtes Phänomen einer ganz bestimmten Regelung unterfalle oder nicht 23 .

30 Ad Erw. 4.3.7.: «Die Auslegung von Art. $28 \mathrm{StGB}$ muss dazu führen, Twitter als Medium anzuerkennen.» So klar die Aussage des Zürcher Einzelgerichts ist, und so sehr sie sich als Folge der Erw. 4.3.1. ff. ergibt, so falsch ist sie. Denn erstens einmal wird im Urteil nicht etwa der Art. 28 StGB «ausgelegt», sondern es wird überlegt, ob Twitter jetzt ein Medium sei und warum; es wird also um es salopp zu sagen - Twitter ausgelegt und nicht die Norm, um deren Anwendung es geht. Selbst wenn man hier dem Verfasser mit rechtstheoretischen und anderen Argumenten widersprechen könnte, bliebe nach dessen Auffassung das Hauptmerkmal von Twitter unberücksichtigt, auf das es vorliegend allein ankommt.

\section{Massenkommunikation $=$ Massen- medium?}

31 «Unsere Mission: Es jedem zu ermöglichen, Ideen und Informationen sofort und ohne Barrieren zu erstellen und zu

23 Gl. M. Schwarzenegger, Anwendungsbereich (Fn. 9), S. 224. teilen.»24 Dieselbe Quelle sagt, dass es 328 Mio. aktive Nutzer im Monat gibt und 1 Milliarde täglicher Besuche von Websites mit eingebetteten Tweets. Die Zahlen sind schon über ein Jahr alt, wird ergänzt. Solche Selbstbeschreibung kann helfen, rechtliche Fragen zu entscheiden.

32 Niemand kann alle Tweets, die täglich versendet werden, bei sich technisch erfassen und schon gar nicht geistig verarbeiten: Es sind Hunderttausende, vielleicht sogar Abermillionen Tweets, die täglich herumgeschickt werden. Und nicht jeder, der ein Twitter-Account hat, bekommt alle Tweets aller anderen von Millionen Twitterern, sowenig wie er seine Tweets oder Retweets an alle andern schickt, sondern eben nur an seine «Follower»25. Dass technisch gesehen möglicherweise alle Tweets über Internet für jedermann abrufbar sind, soweit man über einen Internet-Anschluss verfügt und auch ohne dass man einen TwitterAccount hat, macht das Problem nur noch offensichtlicher. Hier liegt eine unendliche Masse von Information vor, die aber in allen ihren Abermillionen Einzelteilen doch immer nur dasselbe sind: Einzelne Äusserungen eines Einzelnen zu irgendetwas. Wie das Gericht unter Erw. 4.5.1. festhält, besteht das Geschäftsmodell von Twitter darin, dass Nutzer Kurznachrichten weiterverbreiten - man müsste genauer sagen: verbreiten oder weiterverbreiten, wenn man korrekterweise den Tweet als blosse (Erst-) Verbreitung und den Retweet als Weiterverbreitung versteht. Es sind also die Nutzer, die etwas verbreiten. Es ist nicht Twitter als Unternehmen, es sind auch

24 So zu lesen auf Twitter.com, abgerufen am 23. August 2017 um 13.28 Uhr.

25 Vgl. Schwarzenegger, Twibel (Fn. 2), S. 218 f. 
nicht näher bestimmte Teil-Einheiten von Twitter, sondern Twitter stellt nur die Plattform, von mir aus die «Technik» zur Verfügung, auf der eine nur mathematisch endliche, sozial gesehen aber unendliche Vielzahl von Menschen eine ebenso unendliche Vielzahl von Meldungen verbreitet. Niemand trifft eine Auswahl, niemand kontrolliert - soweit ersichtlich - vor der Verbreitung eine Meldung. Dass eventuell nachträglich bestimmte Meldungen technisch gesperrt werden («hate speech» als Stichwort) oder die Verwendung bestimmter Stichworte möglicherweise zur Auslösung (vielleicht sogar automatisierter) Kontrollmechanismen führt, belegt ja geradezu das Fehlen einer präventiven Kontrolle ${ }^{26}$. Auf Existenz und Wirksamkeit solcher «Nachzensur» kommt es allerdings auch nicht an: Twitter dient nicht der Verbreitung von Meldungen des Betreibers, sondern denen seiner Nutzer. Es ist massenhafte Individualkommunikation: Jemand teilt sich einer tatsächlich beschränkten, wenn auch technisch unbeschränkten Vielzahl von Menschen mit, die das, was sie erhalten, ihrerseits weiterleiten können oder auch nicht. Auch darüber bestimmt nicht Twitter, sondern allein der individuelle Nutzer: Keiner muss einen Tweet lesen, keiner muss ihn retweeten, keiner muss einen Retweet lesen - aber jeder kann es tun oder auch lassen. Da das allerdings auch für alle anderen, insbesondere die klassischen Medien gilt, kann daraus, dass man ihre Inhalte konsumieren oder ignorieren kann, nichts für den Medienbegriff

$26 \overline{\text { Vgl. z.B. heisse.de, abgerufen am 18. September }}$ 2017 um 23.08 Uhr; vgl. auch: Rechtliche Basis für Social Media: Erneute Standortbestimmung, Nachfolgebericht des Bundesrates zum Postulatsbericht Amherd 11.3912 «Rechtliche Basis für Social Media» vom 10. Mai 2017, S. 49 f. abgeleitet werden. Dieser erschliesst sich vielmehr nur mit dem Blick auf den Absender, und der kann bei Twitter neben Abermillionen unverbundener Einzelpersonen durchaus auch ein Medienunternehmen sein.

33 Bei Twitter (verstanden als Verbreitungskanal) fehlt es am konstitutiven Element eines Mediums im Sinne des Strafrechts: Der klaren Beschränkung derer, die etwas verbreiten, und der gezielten, inhaltlichen Aufbereitung vor Verbreitung (so marginal die sein mag). Ein Medium ist zwar auch, wenn man so will, Einweg-Kommunikation, aber sie erfolgt geordnet, organisiert, strukturiert und letztlich auch rechtlich verantwortet von einem Medienunternehmen (und sei es eine natürliche Person). Eine Publikation, bei der jeder mitmachen kann, ohne dass jemand darüber die Herrschaft hätte, was er wie und wann macht, ist keine Publikation mehr im Sinne des strafrechtlichen Medienbegriffs. Man muss, so altmodisch das erscheinen mag, aus der historischen Perspektive denken: Die Zeitung/Zeitschrift, ob gedruckt oder online, hat eine Redaktion, eine Organisation, ein (verantwortliches) Medienunternehmen; das ist bei der EinmannRedaktion eines Wochenblättchens nicht anders als bei der selbstverwalteten Links-Grün-Alternativ-Postille oder der Sonntagsausgabe einer Zeitung aus einem Grosskonzern. Sie alle verbreiten eigene Inhalte, auch wenn sie Inhalte Dritter übernehmen, ja selbst nur aus (legal oder illegal) übernommenen Drittinhalten bestünden, und deshalb unterfallen ihre Tweets auch dem Medienbegriff bzw. -privileg des Art. 28 StGB. Radio und Fernsehen, auch das inhaltlich seichteste Lokalradio, hat eine Organisation 
und sendet selbst, gestaltet sein Programm, gibt sich eine wie auch immer zu bewertende Identität; auch die Tweets solcher Absender unterfallen dem Medienstrafrecht. Die Zeitung besteht nicht darin, dass ihre Leser den gesamten Inhalt bestimmen, sowenig wie das Radio allein die Zuhörer reden und das Fernsehen nur die Zuschauer auftreten lässt die Mitwirkung dieser «Nutzer» ist, wenn sie überhaupt stattfindet, im Grundsatz limitiert und kontrolliert. Nur so kann ein Medium im Sinne des Strafrechts entstehen, das dann die - vom Einzelrichter zurecht immer wieder erwähnten - demokratietheoretischen Funktionen auch erfüllen kann ${ }^{27}$.

Wo der Inhalt allein vom Nutzer gemacht wird, und zwar gänzlich unabhängig von den Inhalten anderer Nutzer, und wo zeitgleich Abermillionen von Nutzern Inhalte herstellen und verbreiten, kann kein Medium vorliegen, sondern nur eine Kommunikationsplattform. Auf Twitter findet Massenkommunikation statt, die keinerlei inhaltliche Vorgaben hat. $\mathrm{Zu}$ dem sind weder der Zeitpunkt noch die Anzahl von Tweets begrenzt noch bestehen Vorgaben über deren Gehalt: Tweets und Retweets sind weder durch zeitliche, quantitative oder qualitative Grenzen beschränkt, sondern einzig durch technische Vorgaben, die zugleich den praktischen Empfängerkreis der unendlichen Vielzahl gleichzeitiger und aufeinander folgender Einzelmeldungen beschränkt. Twitter ist, um ein Bild aus der Welt früherer Kommunikation zu bemühen, sozusagen die gleichzeitige Teilnahme vieler an vielen verschiedenen Konferenztelefongesprächen, aus denen sie

$27 \overline{\text { Die auch Schwarzenegger, Anwendungsbereich }}$ (Fn. 9), S. 169 ff. und S. 187 f. zurecht betont. sich folgenlos ausklinken und in andere einklinken können. Bloss findet das in Form schriftlicher, und umfangmässig beschränkter Mitteilungen statt, und jede Mitteilung ist (jedenfalls in der Theorie) einem ganz bestimmten Nutzer als Verfasser zurechenbar. Verfasser ist aber gerade nicht Twitter, sondern Twitter das Unternehmen, das es erlaubt, dass Dritte untereinander schriftlich kommunizieren - eben barrierefrei Informationen zu erstellen und zu teilen, wie oben zitiert. Twitter ist also, um noch ein Bild zu bemühen, das Telefon- oder Glasfaser- oder Stromleitungs- oder Schienennetz oder die Autobahn, aber weder der Gesprächsteilnehmer noch der Strom noch der Zug noch der Reisende oder der Autofahrer. Oder, um erneut das eingängige Bild von Schwarzenegger zu zitieren: Twitter ist die Wand, aber nicht das Plakat ${ }^{28}$. Deshalb ist Twitter auch kein Medium im Sinne des Strafrechts. Es fehlt an der pressemässigen Mitwirkung, es fehlt an allem, was eine «entreprise de média» darstellen könnte.

35 Das Medium richtet sich aktiv an den Konsumenten, der es - grundsätzlich passiv - entweder konsumiert oder ignoriert; selbst seine Reaktion (Protest, Anruf in die Sendung, Leserbrief) macht ihn nicht zum Teil eines Mediums, sondern höchstens zum Teil eines Kommunikationsvorganges innerhalb eines Mediums. Twitter ist auch nicht deshalb Medium, weil viele darin ihre Meinung äussern und verbreiten bzw. mit Hilfe anderer verbreiten können, denn darin unterscheidet es sich letztlich nicht vom Stammtisch, vom «Speaker's Corner» oder jeder anderen Form von Kommunikation; es unterscheidet sich von diesen

28 Schwarzenegger, Twibel (Fn. 2), S. 229. 
lediglich in der Breitenwirkung oder dem Wirkungsgrad in quantitativer Hinsicht. Auch die SMS ist kein Medium, sondern Kommunikation, und daran ändert der durchschlagende Erfolg von WhatsApp nichts: Denn Grösse und Masse können nicht massgebend sein, sowenig wie die Auflagezahl einer Zeitung darüber entscheidet, ob sie Medium sei oder nicht. Wie der Einzelrichter zurecht bemerkte, war auch die in wenigen hundert Exemplaren mit Schreibmaschine und Matrize hergestellte Broschüre Medium im Sinne des Strafrechts (Erw. 4.2.2.) - also kann man umgekehrt die grosse Zahl von Nutzern einer Kommunikationsform nicht als für deren Mediencharakter konstitutives Merkmal betrachten wollen.

Auch über Facebook und Instagram und eine dem Verfasser gänzlich unbekannte Vielzahl anderer «social media» können sich deren Teilnehmer/Nutzer global verbreiten, ohne dass man deshalb auf die Idee gekommen wäre, es handle sich dabei um ein Medium im Sinne des Strafrechts. Eine Plattform, die lediglich die Kommunikation unter Dritten, zumal einer tendenziell unbeschränkten Anzahl, ermöglicht, ist kein Medium, sondern nur eine andere Form von Individualkommunikation, insoweit dem Telefon, dem Stammtisch oder dem Zwiegespräch gleichzusetzen und gerade nicht Radio, Fernsehen oder den herkömmlichen, gedruckten Medien, um die es im Art. 28 StGB geht. Entscheidend dafür, ob einzelne Tweets dem Medienstrafrecht unterfallen können, scheinen mir dafür der Blick auf den Absender und dessen Absichten, insbesondere dessen erkennbares Bemühen, einen Beitrag zur Meinungsbildung zu leisten, die zeitliche Abfolge und die inhaltliche Relevanz.

\section{Vergleich mit Plakatkleben}

37 Nichts zu gewinnen ist schliesslich mit der vom Zürcher Einzelgericht vorgenommenen Gleichsetzung von Retweet und Plakatkleben: Das nicht geklebte, insoweit nicht in medientypischer Weise verbreitete Plakat bleibt Medium, bloss wurde es eben nicht veröffentlicht. Und es ist in der Tat auch viel naheliegender, den Retweet mit dem von der fremden Wand abgehängten und auf der eigenen Wand dann aufgeklebten Plakat zu vergleichen29. Zudem ist der Tweet ungeachtet seiner Weiterverbreitung durch Retweets schon in der Welt und hat jedenfalls Verbreitung bei den (Erst-) Empfängern erfahren; technisch wie theoretisch ist der Retweet nicht notwendig, wenn auch leicht möglich. Auch deshalb scheint es mir sinnlos, zwischen Plakaten, ob geklebt oder nicht, und Tweets, ob retweeted oder nicht, irgendwelche medienrelevanten Vergleichsbeziehungen suchen zu wollen: Dass der Urheber des Plakats ebenso wie der Verfasser eines Tweets, der Redaktor der Zeitung, der Journalist des Online-Mediums oder der Redner am «Speaker's Corner» die möglichst grosse - Öffentlichkeit suchen, haben sie zwar gemeinsam und unterscheidet sie von dem, der mit genau einer Person telefoniert oder redet oder ihr (von Hand oder per SMS) schreibt und dabei vielleicht sogar grössten Wert darauf legt, dass sonst niemand etwas davon mitbekommt. Aber das ist für die Frage des Mediencharakters gerade nicht entscheidend ${ }^{\circ}$, sonst wäre jede an die Öffentlichkeit gerichtete Kommunikation «Medium» im Sinne des Strafrechts; ich lasse die Antwort auf die umgekehrte

29 Schwarzenegger, Twibel (Fn. 2), S. 229.

3o Sondern nur für die Frage der Veröffentlichung. 
Frage, ob jede nicht an die Öffentlichkeit gerichtete Kommunikation allein schon deshalb nicht «Medium» sein kann, offen.

\section{Literatur zu Art. 28 StGB}

38 Das Urteil ist mit Hinweisen auf die einschlägige Lehre, wie erwähnt, sparsam: Twitter ist zu neu, um eine einlässliche Behandlung in den teilweise noch vor 2010 erschienenen Werken erfahren zu haben; allerdings ist auch ein Erscheinungsjahr 2017 kein Garant dafür, dass Twitter an einschlägiger Stelle vorkommt. Was zeigt uns ein - ohne Anspruch auf Vollständigkeit erfolgter Blick in einige der Kommentierungen zu Art. 28 StGB?

Trechsel/Noll/Pieth vertreten einen weiten Medienbegriff inkl. "Internet und was auch immer an neuen Kommunikationsmitteln entwickelt werden mag»;31 die Abgrenzung von der Veröffentlichung überhaupt ist damit allerdings nicht mehr zu leisten.

40 Stratenwerth/Wohlers schliessen zwar die «elektronischen Netzwerke mit Einschluss des Internets» in den Medienbegriff ein, erkennen aber zurecht, dass die Einordnung der Netzwerke, die eine Individualkommunikation ermöglichten, zweifelhaft sei32.

41 Donatsch vertritt in ebenfalls einen sehr weitern Medienbegrifft, ich zitiere vollständig: «Als Medien gelten nicht nur das Fernsehen, das Radio sowie die Pres-

31 Stefan Trechsel/Peter Noll/Mark Pieth, Schweizerisches Strafrecht Allgemeiner Teil I, 7. Aufl. Zürich 2017, S. 229.

32 Günter Stratenwerth/Wolfgang Wohlers, Schweizerisches Strafgesetzbuch, Handkommentar, 3. Aufl., Bern 2013, Art. 28 N 2. se, sondern alle Kommunikationsmittel. Erfasst werden demnach überdies alle Arten von Druckschriften (Blatt, Brief, Bücher, Flugblätter, Plakate, Prospekte, Kataloge etc.), Gemälde, Foto, Film, Kassette, DVD, Videos, der Memory-Stick, die elektronische Textübertragung (Teletext, Videotex, CD-ROM), die telefonische Tonübertragung (Festnetz-, Mobil-, Internet-Telefonie), Mailing-Listen, Newsgroups, der Chat, das WebStreaming (Ton- oder Bildübertragung via Web) und das World Wide Web. Der Begriff des Mediums ist in einem weiten Sinne zu verstehen (BGE 128 IV 65).»33 Dem ist zumindest insoweit zu widersprechen, als dass nicht einfach jede Individualkommunikation und jedes beliebige Kommunikationsmittel dem Medienprivileg unterfallen kann, weil damit zwischen «Medium» und «Veröffentlichung» nicht mehr unterschieden werden kann.

42 Auf die Botschaft des Bundesrats von 1996 verweisen Favre/Pellet/Stoudmann;34 sie machen sich damit eine «conception globale de médias» zu eigen, die aber keine tauglichen Abgrenzungskriterien liefert.

43 Dupuis/Moreillon/Piguet/Berger/Mazou/Rodigari vertreten ebenfalls einen denkbar weiten Medienbegriff, Twitter kommt allerdings in ihrer Aufzählung nicht vor. 35 Auch die weiteren Überle-

$33 \overline{\text { Andreas Donatsch, in Donatsch/Flachsmann/ }}$ Hug/Weder (Hrsg.), StGB-Kommentar, 19. Aufl., Zürich 2013, Art. $28 \mathrm{~N} 2$.

34 Christian Favre/Marc Pellet/Patrick Stoudmann (Hrsg.), Code pénal annoté, 3. Aufl., Lausanne 2011 Art. $28 \mathrm{~N} 1.1$.

35 Michel Dupuis/Laurent Moreillon/Christophe Piguet/Séverine Berger/Miriam Mazou/Virginie Rodigari (Hrsg.), Petit commentaire, Code pénal, 2. Aufl., Basel 2017, Art. 28 N 4. 
gungen ergeben keine Anhaltspunkte dafür, wie man irgendwelche Veröffentlichungen über irgendwelche Kommunikationswege noch vom «média» des Art. 28 StGB abgrenzen könnte36.

44 Werly liefert ebenfalls nichts für eine $\mathrm{Ab}$ grenzung; er bezieht insbesondere die mehrtausendfach verbreitete E-Mail in den Medienbegriff ein ${ }^{37}$. Barrelet/Werly vertreten ebenfalls unter Berufung auf die Botschaft einen weiten Medienbegriff, einschliesslich der «sites offerts sur les autoroutes de l'information »: «L'Internet et les autres réseaux de ce type sont sans nul doute des médias, puisqu'ils sont à la disposition d'un public non déterminé. $\gg 38$ Nur eben: Sinn und Zweck der Bestimmung von Art. 28 StGB kann es gerade nicht sein, jede Veröffentlichung zu erfassen.

In ähnlicher Weise finden wir auch bei Hurtado Pozo einen weiten Medienbegriff: Neben allen klassischen gedruckten auch «les services d'nformation par téléphone» oder «les sites offerts sur Internet».39

Schliesslich ist auch die Aufzählung bei Schwarzenegger eine lange und nicht abschliessende, insb. nimmt er im jüngeren seiner beiden Aufsätze «Twitter» ausdrücklich zunächst unter die Medien auf. 40

36 Vgl. Favre et al. (Fn. 34), a.a.O., Art. $28 \mathrm{~N} 18 \mathrm{ff}$.

Werly (Fn. 11), Art. $28 \mathrm{~N} 14$ f.

38 Denis Barrelet/Stéphane Werly, Droit de la communication, 2. Aufl., Bern 2011, N 1361 und N 1395.

39 José Hurtado Pozo, Droit pénal, Zürich, 2009, $\mathrm{N} 1277$.

40 Schwarzenegger, Anwendungsbereich (Fn. 9), S. 173 f., Schwarzenegger, Twibel (Fn. 2), S. 223.
47 Interpretiert man die Lehrmeinungen statt des Gesetzes - so müsste man wohl sagen: Die grosse Mehrheit würde wohl «Twitter», wenn sie es erwähnen würden, für ein Medium halten. Nach dem vorstehend Gesagten indessen zu Unrecht.

\section{Fazit}

48 Damit bleibt es bei einem zwar unvollständigen Teilergebnis, aber einer klaren Beurteilung: Twitter ist kein Medium im Sinne des Art. 28 StGB, das Medienstrafrecht bzw. Medienprivileg ist auf Twitter nicht anwendbar, sondern Twitter ist Kommunikation, für die alle gewöhnlichen Regeln über Täterschaft und Teilnahme gelten. Eine abschliessende, sozusagen positive Umschreibung dessen, was ein Medium ist, wagt der Verfasser nicht, und angesichts der technischen Entwicklung wäre das wohl auch anmassend bzw. nur von (höchst) beschränkter Bedeutung, wenn überhaupt. Das hindert nicht zu erkennen, dass Twitter jedenfalls kein Medium ist, das denjenigen, der einen Retweet macht, von Strafbarkeit befreien könnte ${ }^{41}$. Ausserdem ist nicht zu sehen, warum der Retweet in die «medientypische Verbreitungskette» gehören soll: Denn der Retweet ist nichts als die Weiterverbreitung einer bereits veröffentlichen (Individual-) Äusserung eines Dritten, und wenn die ehrverletzend ist, dann ist nicht einzusehen, warum das über Twitter als Retweet straflos, im direkten, mündlichen Gespräch aber unbestritten strafbar wäre. Zudem ist ein Retweet für die Funktionsweise von Twitter keineswegs nötig, wenn auch (sehr leicht) möglich. Vergleicht man Twitter als Plattform bzw. den einzelnen

41 Im Ergebnis gleich Schwarzenegger, Twibel (Fn. 2). 
Tweet mit der nächstliegenden von allen anderen Kommunikationsformen, der SMS, ist offensichtlich, dass die Subsumption von Twitter unter den Medienbegriff nicht richtig sein kann.

49 Das Manko, keinen «abstrakten», «allgemeingültigen» Medienbegriff selbst im beschränkten Rahmen des Art. 28 StGB entwickeln zu können, ist zwar unbefriedigend, aber nicht entscheidend: Wenn das Strafrecht mit neuen Phänomenen konfrontiert ist, kann deren Relevanz bzw. Irrelevanz im Lichte der anzuwendenden Norm auch erkannt werden, ohne dass man zu einer darüber hinausreichenden, weiteren Abstrahierung gelangen muss, so wünschbar diese aus intellektuellen wie dogmatischen Gründen wäre. Die faktische Auflösung der Grenzen zwischen Medien und Kommunikation sollte allerdings den Gesetzgeber veranlassen, das Medienstrafrecht bzw. die Besonderheiten von Täterschaft und Teilnahme neu zu ordnen.

\section{Epilog}

5o Der Freispruch durch das Einzelgericht beruhte also auf einer falschen Grundannahme - dem Charakter von Twitter als Medium. Im Ergebnis wäre allerdings nach hier vertretener Auffassung trotzdem der Angeklagte $\mathrm{X}$ freizusprechen gewesen. Der fragliche Tweet, von dem ich eingangs sprach, ist nämlich - entgegen der komplizierten, hier nicht zu referierenden Begründung - keine Ehrverletzung42. Die Bezeichnung eines durch seine zwielichtige Rolle in einer Staatsaffäre bekannten Anwalts mit «Hans ,Dölf Müller» (wobei der Verfasser hier

42 Zweifelnd auch Studer (Fn. 2), S. 130, und Schwarzenegger, Twibel (Fn. 2), S. 222. in Abweichung der Publikation in der ZR und der ausführlichen Darstellung bei Schwarzenegger 43 mit «Hans» und «Müller» bewusst zwei Allerweltsnamen anstelle der richtigen verwendet) ist weder die Gleichsetzung von Müller mit Hitler noch der Vorhalt einer nationalsozialistischen Gesinnung oder sonst anfechtbarer Anschauungen. Zudem rechtfertigt allein schon die Tatsache, dass besagter Anwalt mit dem Inhaber der Domain «adolf-hitler.ch» über einen relevanten Zeitraum hinweg geschäftlich verbunden war (vgl. die Erw. 5.3.3. des Urteils), die Verwendung von «Dölf» in Bezug auf ihn, wenn man den Schluss von «Dölf» auf «Adolf Hitler» - im Gegensatz zum Verfasser - für zwingend hält. Mithin hätte der angeklagte Retweeter X - dessen Namen ich hier ebenfalls im Gegensatz zu Schwarzenegger nicht nenne - nicht etwa wegen Art. 28 StGB, sondern schlicht wegen Fehlen eines Straftatbestandes freigesprochen werden müssen, was auch der dann auferlegten zivilrechtlichen Sanktion die Grundlage entzogen hätte. Eine genauere Darlegung dieser keineswegs als unbedingt mehrheitsfähig erachteten, zivilund strafrechtlichen Einschätzung kann indessen mangels Bezug zur vorliegend behandelten Frage unterbleiben.

$43 \overline{\text { Schwarzenegger, Twibel (Fn. 2), S. } 219 \text { mit wei- }}$ teren Hinweisen zur Vorgeschichte des Tweets bzw. Retweets. 
Urteil des Bezirksgerichts Zürich vom 26. Januar 2016

Art. 28 StGB; Art. 173. StGB; Art. 174 StGB; Art. 322bis StGB; Art. 28 ZGB; Art. 28a ZGB; Art. 49 OR; Art. 426 StPO; Weiterleiten einer ehrenrührigen Kurznachricht über Twitter (Retweet).

Der Kurznachrichtendienst Twitter (www.twitter.com) ist ein Medium im Sinne von Art. 28 StGB (Erwägung 4.3.).

Jedenfalls eine Kurznachricht (Tweet) auf einem Account, der nicht nur von Angehörigen und Bekannten seines Inhabers beachtet wird, ist eine Veröffentlichung im Sinne von Art. 28 StGB (Erwägung 4.4.).

Das Weiterleiten eines ehrenrührigen Tweets (Retweet) ist Teil der für Twitter typischen Verbreitungskette und daher kraft des Privilegs von Art. 28 StGB straflos (Erwägung 4.5.).

Das Privileg von Art. 28 StGB greift nicht bei Rassendiskriminierung, harter Pornographie oder Gewaltdarstellungen (Erwägung 4.6.).

Der Twitter-Account einer Einzelperson hat keinen vom Autor verschiedenen Redaktor und keine andere für die Veröffentlichung verantwortliche Person im Sinne von Art. 322bis StGB (Erwägung 4.7.).

Publikumsbefragungen zur Ermittlung der Auffassung des Durchschnittslesers verlagern das Problem, anstatt es zu lösen (Erwägung 5.3.).

Bei einer Persönlichkeitsverletzung durch einen Retweet kommt neben Geld auch eine Richtigstellung oder Urteilsveröffentlichung durch einen neuen Tweet als andere Form der Genugtuung in Frage (Erwägung 5.4.).

Zwischen einem rechtswidrigen Retweet und der ausgelösten Strafuntersuchung fehlt es wegen Art. 28 StGB am adäquaten Kausalzusammenhang, der freigesprochene Beschuldigte ist nicht kostenpflichtig (Erwägung 6.)

\section{Retweet als Gegenstand des Strafverfahrens}

Der Privatkläger ist Rechtsanwalt und Politiker. Landesweit bekannt wurde er durch die Rolle, die er beim Rücktritt des Nationalbankpräsidenten Philipp Hildebrand gespielt hatte. Der Beschuldigte ist Redaktor der WochenZeitung. In der WoZ vom 14. Juni 2012 veröffentlichte er einen Artikel über den Privatkläger: Als Halter der Internet-Adresse "adolfhitler.ch" war damals "X. AG, Hermann Lei" eingetragen. Das ergab eine Abfrage auf der Website der Stiftung SWITCH, welche Domains mit den Endungen ".ch" und ".li" verwaltet. Der Beschuldigte ging in seinem Artikel der Frage nach, was der Privatkläger mit "adolf-hitler.ch" zu tun hat.

"NewsMän" verbreitet über seinen Twitter-Account Medienberichte, die ihm interessant scheinen. Früher nannte er sich "MusicMän2013". Seine Identität ist nicht bekannt. Am 13. Juli 2012 veröffentlichte "MusicMän2013" über Twitter eine Kurznachricht. Der Tweet wies auf einen Artikel in der NZZ und einen Leserbrief hin, mit dem der Privatkläger darauf reagiert hatte. Artikel und Leser- 
brief drehen sich um einen Dokumentarfilm des Schweizer Fernsehen über den Rücktritt von Philipp Hildebrand. Sie haben nichts mit der Hitler-Domain zu tun. In seiner Kurznachricht bezeichnete "MusicMän2013" den Privatkläger als "Hermann "Dölf" Lei". Jene Twitterer, welche die Tweets von "MusicMän2013" verfolgen, erhielten diese Kurznachricht auf ihrem eigenen Twitter-Account angezeigt. $\mathrm{Zu}$ diesen Followern von "MusicMän2013" gehört auch der Beschuldigte.

Die Staatsanwaltschaft wirft dem Beschuldigten vor, er habe den Tweet von "MusicMän2013" kommentarlos an seine eigenen Follower weitergeleitet. Das Weiterleiten eines Tweets ist denkbar einfach. Der Nutzer braucht lediglich das Retweet-Symbol anzuklicken oder anzutippen, damit der erhaltene Tweet auch auf dem Account der eigenen Follower angezeigt wird. Wegen dieses Retweets erhebt die Staatsanwaltschaft gegen den Beschuldigten Anklage wegen Verleumdung oder Übler Nachrede.

\section{Bisheriger Verlauf des Strafver- fahrens}

Am 16. Juni 2013 zeigte der Privatkläger den Beschuldigten bei der Staatsanwaltschaft an und beantragte dessen Bestrafung wegen Verleumdung.

Er machte geltend, den fraglichen Retweet erst am 7. Mai 2013 entdeckt zu haben, so dass die dreimonatige Antragsfrist (Art. 31 StGB) gewahrt sei. Die Staatsanwaltschaft erledigte das Strafverfahren mit Einstellungsverfügung vom 11. April 2014. Sie bezweifelte die Rechtzeitigkeit des Strafantrags und hielt dafür, der Zusatz "Dölf" sei für die meisten Leser unverständlich oder allenfalls als Hinweis auf die Geschichte mit der Hitler-Domain zu verstehen, keinesfalls werde der Privatkläger damit aber als Anhänger des Nationalsozialismus diskreditiert. Das Obergericht hob die Verfügung vom 11. April 2014 am 26. Januar 2015 auf: Es bestünden keine ernsthaften Anhaltspunkte dafür, dass der Privatkläger den fraglichen Retweet schon früher entdeckt habe, im übrigen handle es sich um einen Zweifelsfall, der untersucht gehöre.

Die Staatsanwaltschaft versuchte, "MusicMän2013" ausfindig zu machen. Das ist bis heute nicht gelungen. Sie befragte den Beschuldigten und den Privatkläger am 1. September 2015 und erhob am 17. September 2015 Anklage. Zur Hauptverhandlung erschienen der Privatkläger, der Beschuldigte und seine Verteidigerin.

\section{Anklagesachverhalt}

Der Beschuldigte hat bestätigt, dass er den Tweet von "MusicMän2013" mit der Bezeichnung "Hermann "Dölf" Lei" weitergeleitet ("retweetet") hat. Die Darstellung des Sachverhalts in der Anklageschrift trifft zu und ist unter den Parteien auch nicht strittig. Der Streit dreht sich um die rechtliche Würdigung des Geschehenen.

\section{Rechtliche Würdigung}

\subsection{Verleumdung und Üble Nach- rede}

Der Üblen Nachrede macht sich schuldig, wer jemanden bei einem anderen eines unehrenhaften Verhaltens oder anderer 
Tatsachen beschuldigt oder verdächtigt, die geeignet sind, seinen Ruf zu schädigen (Art. 173 Ziff. 1 Abs. 1 StGB). Der Üblen Nachrede macht sich ebenfalls schuldig, wer eine solche Beschuldigung oder Verdächtigung weiterverbreitet (Art. 173 Ziff. 1 Abs. 2 StGB). Der Verleumdung macht sich schuldigt, wer solche Beschuldigungen oder Verdächtigungen wider besseres Wissen erhebt oder verbreitet (Art. 174 Ziff. 1 StGB).

Der Vorwurf, Sympathien für das NaziRegime zu haben, ist rufschädigend (BGE 137 IV 313, E. 2.1.1., S. 315 mit weiteren Hinweisen). Fragen kann man sich einzig, ob der Beschuldigte einen derartigen Vorwurf erhoben hat. Die Staatsanwaltschaft und der Privatkläger erblicken diesen Vorwurf im weitergeleiteten Tweet, in dem von "Hermann "Dölf" Lei" die Rede war.

\subsection{Sonderregelung für Veröffent- lichungen in einem Medium}

Wird eine strafbare Handlung durch Veröffentlichung in einem Medium begangen und erschöpft sie sich in dieser Veröffentlichung, so ist, unter Vorbehalt der nachfolgenden Bestimmungen, der Autor allein strafbar (Art. 28 Abs. 1 StGB). Kann der Autor nicht ermittelt oder in der Schweiz nicht vor Gericht gestellt werden, so ist der verantwortliche Redaktor nach Artikel 322bis [StGB] strafbar. Fehlt ein verantwortlicher Redaktor, so ist jene Person nach Artikel 322bis [StGB] strafbar, die für die Veröffentlichung verantwortlich ist (Art. 28 Abs. 2 StGB).

Art. 322bis StGB lautet wie folgt: "Wer als Verantwortlicher nach Artikel $28 \mathrm{Ab}$ sätze 2 und 3 [des Strafgesetzbuchs] eine
Veröffentlichung, durch die eine strafbare Handlung begangen wird, vorsätzlich nicht verhindert, wird mit Freiheitsstrafe bis zu drei Jahren oder Geldstrafe bestraft. Handelt der Täter fahrlässig, so ist diecStrafe Busse."

\subsubsection{Alte und neue Regelung der Presse- bzw. Mediendelikte}

Bereits die 1942 in Kraft getretene Urfassung des schweizerischen Strafgesetzbuchs enthielt eine Sonderregelung für strafbare Veröffentlichungen. Sie war auf strafbare Handlungen beschränkt, die "durch das Mittel der Druckerpresse" begangen werden. Das umfasste sowohl Zeitungen und Zeitschriften als auch "nicht periodische Druckschriften". Grundsätzlich war allein der Verfasser strafbar. Konnten die Untersuchungsbehörden ihn nicht ermitteln, so waren allenfalls der Verleger, der Redaktor oder der Drucker strafbar, nicht aber alle weiteren Mitwirkenden (vgl. Art. 27 StGB in der Fassung von 1937/1942 [BBl 1937 III 625ff.]).

Die heutige Regelung trat am 1. April 1998 in Kraft, damals noch als Art. 27 StGB (heute: Art. 28 StGB). Die Ausdehnung der Sonderregelung von der "Druckerpresse" auf sämtliche Medien hatte vor allem Radio und Fernsehen im Auge, gilt aber nicht nur für sie (vgl. ZELLER in: NIGGLI/WIPRÄCHTIGER, Basler Kommentar, Strafrecht I, 3. Auflage 2013, N 2off. zu Art. 28 StGB).

\subsubsection{Rechtsprechung zum Kreis der geschützten Personen}

Schon im Jahr 1947 befasste sich das Bundesgericht mit der Tragweite des damaligen Art. 27 StGB: Auf die Phase 
vor der Entstehung eines Textes waren die allgemeinen Regeln über die Teilnahme an der Straftat eines andern durchaus anzuwenden. Das Bundesgericht hielt aber auch fest, von all jenen Personen, die sich mit Herstellung und Verbreitung einer Druckschrift befassten, seien allenfalls die in Art. 27 StGB genannten strafbar (Redaktor, Verleger, Drucker, Leiter des Anzeigeteils). Alle anderen, zum Beispiel die Verträger, blieben straflos. Das gilt auch, wenn sie nach den allgemeinen Regeln Gehilfen oder Mittäter einer Ehrverletzung wären (BGE 73 IV 65, S. 67f.). Was das bedeutet, zeigt ein späterer Entscheid anschaulicher: Ein Musiklehrer, der einem Journalisten Unterlagen für einen kritischen Artikel über das Konservatorium Zürich verschafft hatte, kam als Mittäter, Anstifter oder Gehilfe des Journalisten in Frage (BGE 86 IV 145, E. 1, S. 147).

Bereits 1948 erkannte das Bundesgericht, Art. 27 StGB gelte nicht nur für professionell hergestellte Druckerzeugnisse, sondern auch für eine mit Schreibmaschine und Matrize in wenigen hundert Exemplaren hergestellte Broschüre, die Bürger in einer Gemeindewahl verteilt hatten: Es gehe nicht darum, ein bestimmtes technisches Verfahren zu privilegieren. Vervielfältigte Schriften spielten eine wichtige Rolle in öffentlichen Debatten über Politik, Kunst, Literatur und dergleichen, deswegen sei die Strafbarkeit bei ihrer Herstellung und Verbreitung eingeschränkt (BGE 74 IV 129, E. 2, S. 13off.).

Wer alles von der Sonderregelung geschützt ist, zeigt ein Entscheid des Bundesgerichts aus dem Jahr 2002: Einige Lokalpolitiker und Mitglieder der CVP im
Wallis, welche die Fristenlösung beim Schwangerschaftsabbruch ablehnten, beteiligten sich in unterschiedlicher Form an einer Plakataktion, die auf jene Politikerinnen der CVP zielte, die sich für die Fristenlösung einsetzten. Das Bundesgericht sprach jene Personen schuldig, die das Plakat gestaltet oder dafür Informationen beschafft hatten, weil es das Plakat als ehrverletzend einstufte.

Nichtsdestotrotz sprach es all jene Beteiligten frei, die sich auf das Plakatieren beschränkt hatten. Unter dem alten wie auch unter dem neuen Recht bleibe straflos, wer eine ehrverletzende Schrift nur verbreite. Der Buchhändler, Kioskmitarbeiter oder Zeitungsverkäufer, aber auch wer Traktate verteile oder Plakate klebe, der Briefträger usw., sie alle seien von Art. 28 StGB geschützt, der nur den Autor für strafbar erkläre. Das Privileg gelte nicht nur für Angestellte eines Medienunternehmens. Auch als Anstifter, Gehilfe oder Mittäter komme nur in Frage, wer nicht Teil der Herstellungs- und Verbreitungskette eines Medienerzeugnisses sei (BGE 128 IV 53, insb. E. 5e, S. 66ff.).

\subsubsection{Ehrverletzungsdelikte in der Variante des Weiterverbrei- tens}

In den zusammengefassten Entscheiden ist vor allem davon die Rede, dass Art. 28 StGB an die Stelle der allgemeinen Regeln über die Gehilfenschaft, die Anstiftung und die Mittäterschaft (Art. 24ff. StGB) trete. Das ist nicht alles. Die Bestimmungen über die Üble Nachrede und die Verleumdung machen das Weiterverbreiten ehrenrühriger Behauptungen oder Verdächtigungen zu einem eigenständigen Delikt (Art. 173 Ziff. 1 Abs. 2 
StGB; Art. 174 Ziff. 1 Abs. 2 StGB). Die vom Bundesgericht beispielhaft zitierten Plakatkleber, Kioskmitarbeiter usw. erfüllen den Tatbestand des Weiterverbreitens regelmässig. Nichtsdestotrotz erklärte das Bundesgericht, die Plakatkleber blieben straflos. Art. 28 StGB schützt demnach nicht nur, soweit es um Anstiftung, Gehilfenschaft oder Mittäterschaft geht. Auch die zum eigenständigen Delikt ausgestaltete Teilnahme durch Weiterverbreiten ist mit Art. $28 \mathrm{StGB}$ von der Strafbarkeit ausgenommen, solange sich die Täter innerhalb der für das Medium typischen Herstellungs- und Verbreitungskette bewegen. Davon geht auch das Bundesgericht aus.

\subsection{Twitter als Medium}

\subsubsection{Sprachgebrauch}

Für Twitter, Facebook, Google+ und ähnliche Plattformen ist sowohl der englische Ausdruck "social media" als auch dessen eingedeutschte Variante gebräuchlich. Mit dem Wortlaut von Art. 28 StGB ist es vereinbar, Veröffentlichungen auf Twitter dieser Regelung zu unterstellen.

\subsubsection{Entstehung der heutigen Fas- sung von Art. 28 StGB}

Als die heutige Fassung von Art. 28 StGB entstand, hatte das Internet bei Weitem noch nicht die heutige Bedeutung. Twitter gab es noch nicht. Der historische Gesetzgeber hatte vor allem Radio und Fernsehen vor Augen, wollte aber eine Regelung schaffen, die alle Medien gleich behandelt. Die Botschaft des Bundesrates erwähnt das Internet denn auch in einem Atemzug mit in Vergessenheit geratenen Kommunikationsformen wie Teletext und Videotex (BBl 1996 IV 527). Der Gesetzgeber wählte das farblose, umfassende Wort "Medium", wo er auch hätte "Radio und Fernsehen" schreiben können. Die Entstehungsgeschichte der heutigen Fassung von Art. 28 StGB ist nicht ausschlaggebend, spricht aber eher dafür, Twitter als Medium zu behandeln.

\subsubsection{Stellung von Art. 28 StGB im gesamten Regelsystem}

Zugleich mit der Neuregelung der Mediendelikte hat das Parlament den Quellenschutz geregelt (heute: Art. 28a StGB und Art. 172 StPO). Auch um zu entscheiden, wie weit der Quellenschutz geht, hatte sich das Bundesgericht damit $\mathrm{zu}$ befassen, was ein Medium bzw. ein periodisch erscheinendes Medium ist: Die Täterin nutzte die Kommentarfunktion auf der Website des Schweizer Fernsehens, um unter dem Pseudonym "Michael Schwizer" launige Kommentare abzugeben, die ein ehemaliger Arbeitskollege als Anspielung auf ihn erkannte und für ehrverletzend hielt. Das Bundesgericht stellte ausdrücklich einen Zusammenhang zwischen Art. 28 StGB (Strafbarkeit von Veröffentlichungen) und Art. 28a StGB (Quellenschutz) her und schützte das Schweizer Fernsehen. Es hatte sich geweigert, den Namen der Bloggerin preiszugeben. Auch die Kommentarfunktion der Website des Schweizer Fernsehens sei ein Medium bzw. Teil eines Mediums (zum Ganzen: BGE 136 IV 145, E. 3.2 und 3.3, S. 149f.; Urteil Nr. GG110138-L des Bezirksgerichts Zürich vom 30. September 2011).

Twitter und ein Blog auf einer Website sind vergleichbar. Der Begriff "Medium" in Art. 28 StGB und Art. 28a StGB/Art. 172 StPO ist einheitlich auszulegen. Das 
legt es nahe, Twitter genau so wie einen Blog auf der Website des Schweizer Fernsehens als Medium im Sinne von Art. 28 StGB zu behandeln.

\subsubsection{Schutz öffentlicher Debatten als Regelungszweck von Art. 28 StGB}

Die deutliche Begrenzung des Personenkreises, der sich durch eine Veröffentlichung strafbar machen kann, dient dem freien Austausch der Meinungen, wie er auch durch die Bundesverfassung und die Europäische Menschenrechtskonvention geschützt ist (Art. 16f. BV; Art. 10 EMRK). Dieser Regelungszweck spricht für den Einbezug von Twitter. Der Tweet, um den es hier geht, bezog sich auf politisch relevante Debatten. Sowohl die Hintergründe und Begleitumstände des Rücktritts eines Nationalbankpräsidenten, als auch die Frage, was ein Politiker mit der Domain adolf-hitler.ch zu tun hat, sind ein legitimer Gegenstand öffentlicher Diskussion. Selbstverständlich dient Twitter auch dem Austausch von Banalitäten, privatem Klatsch und Tratsch oder rein organisatorischer Informationen über Vereinsanlässe und dergleichen. Darauf ist Twitter aber nicht beschränkt. Zahlreiche Politiker, Unternehmen, Behörden, Parteien usw. nutzen Twitter, um sich Gehör zu verschaffen. Den überzeugendsten Beleg für die meinungsbildende Funktion von Twitter lieferten die Mächtigen der Volksrepublik China. Sie blockierten den Dienst einige Tage bevor sich die blutige Niederschlagung der Proteste auf dem Platz des Himmlischen Friedens zum zwanzigsten mal jährte. Twitter ist bis heute nur in Hong Kong und Macao problemlos zugänglich. Twitter dient dem freien Austausch von Informationen und Meinun- gen und ist deshalb ein Medium im Sinne von Art. 28 StGB.

\subsubsection{Missbrauchsgefahren}

Art. 28 StGB hat allerdings nicht zum Zweck, folgenlose Ehrverletzungen für jedermann zu ermöglichen oder das Internet zum rechtsfreien Raum zu machen. Auf die Gefahren eines Missbrauchs strafloser Retweets ist deshalb einzugehen.

Es ist denkbar, dass sich der Verfasser ehrverletzender Texte hinter einem Retweet versteckt und in Tat und Wahrheit selbst für den ursprünglichen Tweet auf einem anonymen Account oder dem Account einer Person im Ausland sorgt. Technisch ist das einfach zu bewerkstelligen. Recht schwierig ist es jedoch, eine derartige Fälschung überzeugend aussehen zu lassen. Ein kurz vor einem ehrverletzenden Retweet eröffneter anonymer Account mit wenigen Followern und einigen pro forma Tweets wird Staatsanwaltschaften und Gerichte nicht überzeugen. Freunde im Ausland müsste ein Täter erst überzeugen, sich für so etwas herzugeben, und meist ist es auch nicht plausibel, weshalb sich plötzlich eine Person aus der Ferne einmischt. Wer sich auf Twitter mit Verbalinjurien eindeckt, hat meist eine Vorgeschichte im realen Leben. Auch jene Bloggerin, deren Blogs zu BGE 136 IV 145 führten, konnte die Untersuchungsbehörde trotz Quellenschutz ausfindig machen. Privatkläger und Angeklagte hatten eine langwierige Vorgeschichte, die von Konflikten am ehemals gemeinsamen Arbeitsplatz geprägt war. Aufgrund des Inhalts der anonymen Blogs war klar, von wem sie stammen mussten (vgl. zum Nachspiel von BGE 136 IV 145: Urteil Nr. 
GG110138-L des Bezirksgerichts Zürich vom 30. September 2011). Das ist typisch, denn das reine Cybermobbing ist selten. Es sind dieselben Personen, die ihre Opfer online und offline schikanieren. Gelegentlich wird es Tätern gelingen, dank solcher Tricks anonym zu bleiben, so wie auch nicht jeder Diebstahl und bei weitem nicht jede Verkehrsregelverletzung aufgeklärt wird. Die Missbrauchsrisiken sind jedoch überschaubar. Es gibt sie auch andernorts im Internet, etwa in den Kommentarfunktionen, die das Bundesgericht dem Quellenschutz unterstellt, und bei den althergebrachten, papierenen Formen der Kommunikation. Das kann nicht dazu führen, Twitter trotz gegebener Voraussetzungen abzusprechen, ein Medium zu sein.

\subsubsection{Wirksamer Persönlichkeits- schutz im Zivilrecht}

Hinzu kommt, dass den Betroffenen nicht allein das Strafrecht zu Gebot steht, um sich gegen ehrenrührige Retweets zu wehren. Zivilrechtlich gibt es keine Privilegierung der Herstellungs- und Verbreitungskette der Medien (BGE 128 IV 53, E. 8, S. 72f.). Der Betroffene kann gegen jeden klagen, der an einer Persönlichkeitsverletzung mitwirkt, also auch gegen den Retweeter (Art. 28 Abs. 1 ZGB). Der Kläger kann eine Berichtigung oder die Beseitigung rechtswidriger Inhalte erwirken, zudem Schadenersatz und Genugtuung, wenn der Täter vorsätzlich oder fahrlässig gehandelt hat (Art. 28a ZGB; Art. 41ff. OR). Die Anwendung von Art. 28 StGB auf Retweets lässt Betroffene nicht schutzlos. Die zivilrechtlichen Folgen einer Persönlichkeitsverletzung einschliesslich der anfallenden Verfahrenskosten sind als Anreiz für korrektes
Verhalten im Internet mindestens so wirksam wie eine bedingte Geldstrafe.

\subsubsection{Twitter als Medium}

Die Auslegung von Art. 28 StGB muss dazu führen, Twitter als Medium anzuerkennen.

\subsection{Veröffentlichung in einem Medium}

Fragen kann man sich jedoch, ob jeder Tweet eine "Veröffentlichung in einem Medium" (Art. 28 Abs. 1 StGB) ist. Technisch ist jeder Tweet öffentlich: Wer irgendwo auf der Welt unzensierten $\mathrm{Zu}-$ gang zum Internet hat, kann jeden Tweet abrufen, dafür braucht man nicht "Follower" des Verfassers zu sein, es bedarf nicht einmal eines Twitter-Accounts. Die Tweets des Privatklägers sind unter <https://twitter.com/hermannlei> abrufbar, jene des Beschuldigten unter <https://twitter.com/[twitter-handle des Beschuldigten]> und jene von "NewsMän" unter <https://twitter.com /kuedder $>$. Tatsächlich von einer halbwegs breiten Öffentlichkeit wahrgenommen werden indes längst nicht alle Twitter-Accounts. Es ist fraglich, ob auch ein Tweet auf einem Account, der nur von den Freunden und Verwandten seines Inhabers wahrgenommen wird, eine Veröffentlichung ist. Dagegen spricht, dass bei solchen Accounts die Öffentlichkeit eher theoretisch ist. Wie mit solchen Fällen umzugehen wäre, kann jedoch offen bleiben. Der Politologe Claude Longchamp hat auf seinem Blog eine Laudatio auf "NewsMän" verfasst, und dieser hat eine vierstellige Zahl von Followern. Das sind weit mehr, als Familie, Freunde und Bekannte, auch bei einer gut vernetzten Person. "NewsMän" verschafft sich mit 
seinen Tweets mindestens so viel Gehör und Öffentlichkeit wie jene engagierten Bürger, die in den vierziger Jahren mit Schreibmaschine und Matrize zweihundert Broschüren herstellten. Seine Tweets sind auch dann eine Veröffentlichung im Sinne von Art. 28 StGB, wenn man darauf abstellt, ob ein Account tatsächlich von der Öffentlichkeit beachtet wird.

\subsection{Medientypische Verbreitungs- kette}

Von der Strafbarkeit ausgenommen ist nur das Weiterverbreiten ehrenrühriger Äusserungen innerhalb der medienspezifischen Verbreitungskette (vgl. auch ZELLER, a.a.O., N 57ff. zu Art. 28 StGB). Bei den seit vielen Jahren gebräuchlichen Methoden, sich in der Öffentlichkeit Gehör zu verschaffen, ist ziemlich klar, was damit gemeint ist. Abgesehen von BGE 128 IV 53 war das kaum je Gegenstand höchstrichterlicher Entscheide. Hier stellt sich die Frage, ob der Retweet zu der für Kurznachrichten auf Twitter typischen und üblichen Verbreitungskette gehört.

\subsubsection{Konzept und Geschäftsmo- dell von Twitter}

Die Betreiber von Twitter haben es darauf angelegt, dass die Nutzer Kurznachrichten weiterverbreiten. Ein Klick oder ein Antippen des Touchscreens genügt. Ein Stück weit leben die sozialen Medien davon, dass die Nutzer die Inhalte auswählen. Was vielen lesenswert erscheint, wird auch über mehrere Accounts weitergeleitet ("retweetet") und vielen Nutzerinnen und Nutzern im eigenen Account angezeigt. Anderes bleibt zwar theoretisch von mehr als einer Milliarde
Menschen abrufbar, wird aber nur auf den Accounts der Follower des ursprünglichen Verfassers angezeigt und auch dort bald von neueren Tweets nach unten verdrängt.

Diese Auswahl der Inhalte durch die Nutzer und die Verknüpfung der Nutzer untereinander ist auch aus kommerziellen Gründen gewollt. Twitter verdient Geld mit Werbeeinblendungen und mit dem Verkauf von Daten. Bestimmte Inserenten bezahlen Twitter nach Massgabe der Anzahl Retweets ihrer Anzeige. Auch die Analyse der verkauften Daten durch Dritte wird ergiebiger, wenn ersichtlich ist, wer wessen Follower ist und wer was favorisiert, ignoriert oder wer was an welchen Personenkreis retweetet (zum Ganzen: VINDU GOEL, For Twitter, Key to Revenue Is No Longer Ad Simplicity, New York Times vom 17. September 2013, S. B1). Das Retweeten ist Teil des Konzepts von Twitter und auch wichtig für dessen kommerziellen Erfolg. Es ist Teil der von Twitter geplanten und gewollten Verbreitungskette eines Tweets.

\subsubsection{Tatsächliche Nutzung}

Nicht nur die Absichten der Betreiber von Twitter, auch das Verhalten der Nutzer lässt den Retweet als Teil der für Twitter typischen Verbreitungskette einer Kurznachricht erscheinen. Retweeten ist keine Seltenheit. Das zeigt ein Blick auf den Twitter-Account eines beliebigen Politikers oder Journalisten, kein anderes Bild ergibt sich bei den Accounts des Privatklägers und des Beschuldigten. Das hat sich bereits im Sprachgebrauch niedergeschlagen. Jedenfalls auf Englisch ist häufig die Rede davon, ein Text, ein Bild oder ein Video habe sich wie ein Virus auf den sozialen Medien ausgebreitet ("It 
went viral."). Das Bild des Virus, der sich von Träger zu Träger ausbreitet, konnte nur entstehen, weil die Nutzer der sozialen Medien Inhalte tatsächlich eifrig wieterleiten. Das gilt auch für die Twitterer.

\subsubsection{Parallelen bei althergebrach- ten Kommunikationsformen}

Bei Zeitungen und Zeitschriften hat die Weiterverbreitung durch Leserinnen und Leser kaum eine Bedeutung. Zeitungen kommen über bezahlte Mitarbeiter eines Kiosk zu den gelegentlichen Leserinnen und Lesern und über bezahlte Verträgerinnen $\mathrm{zu}$ den Abonnenten. Sicher kommt es gelegentlich vor, dass Leser Zeitungen weiter verbreiten, indem sie diese im Zug liegen lassen oder indem sich Nachbarn gegenseitig TagesAnzeiger und NZZ in den Briefkasten legen, damit nicht beide beides abonnieren müssen. Das ist aber weder entscheidend für den geschäftlichen Erfolg einer Zeitung, noch ist es zahlenmässig bedeutsam.

Auf all das kann es jedoch nicht ankommen. Jahrzehnte vor dem Internet hat das Bundesgericht klargestellt, dass unerheblich ist, ob jemand berufsmässig oder privat handelt. Es spielt auch keine Rolle, ob jemand ein professionelles Medienprodukt verbreitet oder ein nach Feierabend mit einfachen Mitteln hergestelltes, laienhaftes Werk.

Der Retweet ist durchaus vergleichbar mit dem Wirken jener Personen, die im Rahmen der Plakataktion der CVP im Unterwallis Plakate geklebt haben. Auch sie kannten die verbreiteten Inhalte. Sie handelten aus freien Stücken, nicht weil sie damit ihren Lebensunterhalt verdienten, und sie erreichten die Öffentlichkeit.
Hinzu kommt, dass es bedeutend mehr Identifikation mit einem Inhalt und Engagement braucht, um Plakate zu kleben als um Tweets per Mausklick weiterzuleiten. Wäre das strafbar, würden die Gerichte von bedeutend höherer krimineller Energie sprechen. Jene Wertungen, die in BGE 128 IV 53 zu Freisprüchen führten, sprechen für die Straflosigkeit des Retweets.

\subsubsection{Retweet als Teil der medien- typischen Verbreitungskette}

Zusammenfassend ist festzuhalten, dass der Retweet ein Glied der für Kurznachrichten auf Twitter typischen, üblichen und von den Betreibern gewollten Verbreitungskette ist. Das Retweeten einer ehrenrührigen Kurznachricht muss deshalb gestützt auf Art. 28 Abs. 1 StGB straflos bleiben, obwohl es den Tatbestand des Weiterverbreitens im Sinne von Art. 173 Ziff. 1 Abs. 2 StGB (Üble Nachrede) bzw. Art. 174 Ziff. 1 Abs. 2 StGB (Verleumdung) erfüllt.

\subsection{Mediendelikt}

Die Privilegierung der medienspezifischen Verbreitungskette greift nur bei Straftaten, die sich in der strafbaren Veröffentlichung erschöpfen (Art. 28 Abs. 1 StGB). Das ist bei Ehrverletzungsdelikten der Fall, um sie ging es in allen zitierten Bundesgerichtsurteilen zu Art. 28 StGB. Der Vollständigkeit halber sei erwähnt, dass das Bundesgericht Art. 28 StGB nicht auf Rassendiskriminierung, harte Pornographie oder Gewaltdarstellungen anwendet. Das wäre mit dem Wortlaut, aber nicht mit dem Zweck von Art. 28 StGB vereinbar (BGE 125 IV 206, E. 3c, S. 211f.). 


\subsection{Redaktor oder für die Veröf- fentlichung verantwortliche Person?}

Da die Identität von "NewsMän" bis heute nicht bekannt ist, stellt sich die Frage, ob der Beschuldigte als verantwortlicher Redaktor oder für die Veröffentlichung des Tweets verantwortliche Person nach Art. 322bis StGB zu bestrafen ist. Der Beschuldigte ist nicht der Redaktor von "NewsMän" und er hatte auch keinen Einfluss auf den Entscheid von "NewsMän", einen Tweet mit der Bezeichnung "Hermann "Dölf" Lei" abzusetzen. Der Tweet war bereits öffentlich, als der Beschuldigte ihn auf seinem eigenen Twitter-Account angezeigt erhielt. Ein Schuldspruch wegen der Nichtverhinderung einer strafbaren Veröffentlichung würde den Wortlaut von Art. 322bis StGB überdehnen. Der Beschuldigte war nicht in einer Position, in welcher er die Veröffentlichung von "NewsMän" hätte verhindern können.

Bei einem Twitter-Account dürfte es nur ausnahmsweise einen vom Autor der Tweets verschiedenen Redaktor oder eine andere, für die Veröffentlichung verantwortliche Person als den Autoren selbst geben. In der Regel veröffentlicht der Autor im Alleingang durch einen Mausklick. Anders verhält es sich bei jenen Twitter-Accounts, hinter denen ein ganzes Team steht. Bei einem TwitterAccount eines Unternehmens, einer Behörde, einer Partei usw. kann es durchaus eine Redaktion bzw. einen Verantwortlichen geben. Ob "NewsMän" eine Einzelperson ist oder ob ein ganzes Team hinter dem Account steht, ist nicht bekannt. Jedenfalls wirft die Anklage dem Beschuldigten nicht vor, Teil eines solchen Teams zu sein, und es gibt auch keinerlei Hinweise darauf, dass es so wäre.

\subsection{Freispruch}

Der Beschuldigte ist nicht der Autor der Bezeichnung "Hermann "Dölf" Lei". Er ist von Schuld und Strafe freizusprechen, weil er sich mit seinem Retweet innerhalb der für einen Tweet typischen Verbreitungskette bewegt hat.

\section{Zivilansprüche}

Anders als nach der Zürcher Strafprozessordnung entscheidet das Gericht heute auch bei einem Freispruch über Zivilansprüche, wenn der Sachverhalt spruchreif ist (Art. 126 Abs. 1 lit. b StPO). Der Sachverhalt, auf den es ankommt, steht fest und die Parteien bestreiten ihn nicht. Über die Zivilansprüche des Privatklägers ist zu urteilen.

\subsection{Zivilrechtlicher Persönlich- keitsschutz}

Wer in seiner Persönlichkeit widerrechtlich verletzt wird, kann zu seinem Schutz gegen jeden, der an der Verletzung mitwirkt, das Gericht anrufen (Art. 28 Abs. 1 ZGB). Eine Verletzung ist widerrechtlich, wenn sie nicht durch Einwilligung des Verletzten, durch ein überwiegendes privates oder öffentliches Interesse oder durch Gesetz gerechtfertigt ist (Art. 28 Abs. 2 ZGB).

\subsubsection{Persönlichkeitsverletzung}

Der Schutz der Persönlichkeit durch das Zivilrecht geht einiges weiter als der strafrechtliche Schutz der Ehre. Während des Strafrecht nur bei Aussagen greift, die den Geschädigten als charakterlich anständigen Menschen in Frage stellen, 
kann eine zivilrechtliche Persönlichkeitsverletzung auch Fragen betreffen, die um die Qualitäten eines Menschen im Beruf kreisen, etwa als Politiker, Handwerker, Unternehmer, Wissenschaftler oder dergleichen. Vorwürfe, ein Anhänger des Nationalsozialismus zu sein oder nur schon das Wirken jenes Regimes zu verharmlosen, sind auch strafrechtlich relevant. Dass derartige Vorwürfe auch eine zivilrechtliche Persönlichkeitsverletzung sind, bedarf keiner näheren Erläuterung (BGE 129 III 49, E. 2.3; BGE 111 II 209). Detailliert zu prüfen ist jedoch, ob sich ein derartiger Vorwurf rechtfertigen lässt und ob ihn der Beschuldigte überhaupt erhoben hat.

\subsubsection{Rechtfertigung durch über- wiegendes öffentliches Inte- resse}

Der Privatkläger ist zumindest zur relativen Person der Zeitgeschichte geworden, indem er eine wichtige Rolle gespielt hatte bei der Weiterleitung von Verdachtsmomenten auf Insidergeschäfte, die zum Rücktritt des damaligen Präsidenten der Nationalbank führten. Er übt auch heute öffentliche Ämter aus. Bei aktiven Politikern sind sogar politische Aktivitäten, die Jahrzehnte zurück liegen, legitimer Gegenstand öffentlicher Diskussion (BGE 111 II 209, insb. E. 3c, S. 213f.). In einem Zeitungsartikel der Frage nachzugehen, was der Privatkläger mit der Domain adolf-hitler.ch zu tun hat, war rechtens. Angesichts seiner Rolle beim Rücktritt des SNB-Präsidenten, aber auch, weil er damals wie heute dem Kantonsrat des Kantons Thurgau angehörte, bestand ein legitimes Informationsbedürfnis der Öffentlichkeit (vgl. BGE 127 III 481, E. 2c/aa und E. 2c/bb, S. 488ff.). Der Privatkläger kann nicht verlangen, dass der
Beschuldigte darüber nichts veröffentlicht. Er kann aber sehr wohl verlangen, dass der Beschuldigte darüber nichts Unwahres veröffentlicht. Falschmeldungen sind nur ganz ausnahmsweise durch ein überwiegendes öffentliches Interesse gerechtfertigt (BGE 129 III 49, E. 2.2, S. 51f.).

\subsection{Ergebnis der Recherchen des Beschuldigten}

Wäre der Privatkläger ein Anhänger oder Verharmloser des Nationalsozialismus, dann dürfte man das auch öffentlich sagen und die Diskussion darüber, was mit der Bezeichnung "Hermann "Dölf" Lei" gemeint sei, würde sich erübrigen. Es ist deshalb kurz darauf einzugehen, was die Recherchen des Beschuldigten ergeben haben und was nicht:

\subsubsection{Inhalte auf adolf-hitler.ch}

"www.adolf-hitler.ch" war nie eine Propagandaseite. W., ein Klient des Beschuldigten, bestimmte, was dort zu sehen war. Er sprach mit dem Beschuldigten und sagte ihm, er habe bewusst nur den Wikipedia-Artikel über Adolf Hitler aufgeschaltet. W. zeigte dem Beschuldigten ein Kündigungsschreiben eines Webhosting-Unternehmens. Es wollte die von W. betriebenen Seiten nicht mehr aufschalten. Dieses Unternehmen beanstandete andere, von W. betriebene InternetAdressen als ehrverletzend. Die Inhalte von "adolf-hitler.ch" bezeichnete es dagegen als rechtlich nicht relevant, doch errege die Domain nur schon aufgrund ihres Namens Aufsehen. Das Webhosting-Unternehmen fürchtete um seinen Ruf und wollte nichts mit adolfhitler.ch zu tun haben. Das Kündigungsschreiben belegt, dass die Aus- 
künfte von W. korrekt waren. Das Webhosting-Unternehmen hätte die Inhalte nicht als unbedenklich bezeichnet, wenn es sich um Nazi-Propaganda gehandelt hätte. W. erklärte dem Beschuldigten, er registriere über die X. AG eine vierstellige Anzahl von Internet-Adressen. Er bzw. die X. AG würden damit Geld verdienen, dass sie dort Werbung aufschalten. Adolf Hitler werde oft gegoogelt. Die Domain adolf-hitler.ch war eine kommerziell motivierte Geschmacklosigkeit, mehr aber nicht.

\subsubsection{Kontrolle über adolf-hitler.ch}

Die Verbindung von adolf-hitler.ch zum Privatkläger besteht darin, dass der Privatkläger im Jahr 2010 die X. AG gegründet hat und nach der Gründung ein halbes Jahr lang deren einziger Verwaltungsrat war. Dann wurde W. einziger Verwaltungsrat, das ist er bis heute. Die X. AG hatte ihr Domizil von der Gründung bis im Jahr 2013 beim Anwaltsbüro des Privatklägers. Dann verlegte die X. AG ihren Sitz. All das ergibt sich aus den Handelsregistern der jeweiligen Sitzkantone.

Das Kündigungsschreiben an W. im März 2009 zeigt, dass er die Domain adolfhitler.ch bereits beherrschte, bevor der Privatkläger die X. AG für ihn gegründet hat. Dass die Stiftung SWITCH auf ihrer Website noch im Sommer 2012 als Halter der Domain "X. AG Hermann Lei" angab, war zumindest missverständlich. Einziger Verwaltungsrat der X. AG war damals bereits seit gut zwei Jahren W. Die X. AG hatte lediglich ihr Domizil beim Anwaltsbüro des Klägers. Das bedeutet im Wesentlichen, dass jedermann der X. AG Mitteilungen rechtsgültig an die Büroadresse des Privatklägers zustellen konnte. Dass der Privatkläger die Domiziladresse zur Verfügung stellte, bedeutet aber nicht, dass er in der X. AG das Sagen hatte.

Eine weiter gehende Verbindung des Privatklägers $\mathrm{zu}$ adolf-hitler.ch haben die Recherchen des Beschuldigten nicht zu Tage gefördert. Selbstverständlich sind die geschäftlichen Aktivitäten eines Politikers legitimer Gegenstand öffentlicher Debatte. Dass der Privatkläger als Verwaltungsrat und später als Domiziladresse für eine Aktiengesellschaft wirkte, die sich aus kommerziellen Gründen eine Geschmacklosigkeit mit der Domai adolfhitler.ch leistete, durfte der Beschuldigte veröffentlichen. Deren Urheber war jedoch W., nicht der Privatkläger. Aus der Verbindung des Privatklägers zu adolfhitler.ch lässt sich nicht der Schluss ziehen, er sei ein Neonazi, Revisionist oder dergleichen.

\subsubsection{Umfeld des Privatklägers}

Der Artikel hat auch ergeben, dass W. auf zahlreichen Blogs Ansichten vertritt, die sich rechts vom bürgerlichen Mainstream bewegen. W. unterhielt offenbar auch einen Blog, der die damalige Bundesrätin Micheline Calmy-Rey verunglimpfte. Der Rechtsdienst des EDA wandte sich deswegen an W., der Privatkläger kritisierte diese Intervention in der Zeitung Schweizerzeit als "massiven Einschüchterungsversuch". Der Artikel erwähnt weiter, dass der Privatkläger einen Politiker der Schweizer Demokraten vor Gericht verteidigte. Dieser hatte sich wegen Rassendiskriminierung zu verantworten, weil er in der Parteizeitung [gemeint wohl: der Schweizer Demokraten] gefordert hatte, keine Muslime einzubürgern. Die Recherchen haben erge- 
ben, dass sich im Umfeld des Privatklägers Personen befinden, die prononciert rechts denken und sich auch öffentlich so äussern. Das macht weder den Privatkläger, noch W. oder den vom Privatkläger verteidigten Politiker zu Anhängern oder Verharmlosern des Nationalsozialismus.

\subsubsection{Zusammenfassung}

Der Privatkläger ist kein Anhänger oder Verharmloser des Nationalsozialismus. Die Recherchen des Beschuldigten haben dafür keine ernsthaften Anhaltspunkte zu Tage gefördert. Dass der Privatkläger Positionen rechts des bürgerlichen Mainstreams vertritt, ändert daran nichts. Der Beschuldigte will denn auch keinen entsprechenden Vorwurf erhoben haben. Er sieht in der Bezeichnung "Dölf", die er weitergeleitet hat, lediglich einen Hinweis auf die Angelegenheit mit der Hitler-Domain.

\subsection{Wirkung auf den "Durch- schnittsleser" als Massstab}

\subsubsection{Die Figur des Durchschnitts- lesers und ihre Fragwürdig- keit}

Bei Veröffentlichungen, die von mehr als einer Hand voll Personen wahrgenommen werden, lässt sich nicht bei jedem einzelnen Leser feststellen, wie er einen Text tatsächlich verstanden hat. Ausschlaggebend ist, wie ein "Durchschnittsleser" die fragliche Äusserung versteht. Mit einzubeziehen ist der gesamte Kontext der fraglichen Äusserung (zum Ganzen: BGE 127 III 481, E. 2b/aa, S. 487, mit weiteren Hinweisen). Zahlreiche Medienjuristen kritisieren diese Praxis. Die Frage, wie diese oder jene Äusserung auf den durchschnittlichen Leser wirke, lasse sich nicht aufgrund der Lebenserfahrung beurteilen, dafür sei eine vertiefte argumentative Auseinandersetzung wenn nicht gar eine Publikumsbefragung notwendig (vgl. act. 32 S. 6f. und MISCHA CHARLES SENN, Der "gedankenlose" Durchschnittsleser als normative Figur?, medialex 1998 S. 15off.).

Sicherlich sollen die Gerichte nicht einfach apodiktisch erklären, der Durchschnittsleser verstehe einen Text so und nicht anders. Die Gerichte sollen sich so konkret wie möglich damit auseinandersetzen, wer eine Veröffentlichung wahrgenommen hat, welches Vorwissen die Adressaten haben und welche Schlüsse sie ziehen. Publikumsbefragungen an die Stelle richterlicher Überlegungen treten zu lassen, würde das Problem aber nur verlagern: Würde man Versuchspersonen etwa den fraglichen Retweet vorlegen, müsste das Gericht oder ein Gutachter ja auch auswählen, was für Versuchspersonen repräsentativ für die Follower des Beschuldigten oder jene von "NewsMän" sind. Ferner wäre zu entscheiden, ob die Versuchspersonen den WoZ-Artikel vorher zum Lesen erhalten oder nicht. Solch teuren Abklärungen mit zweifelhaftem Beweiswert haben sich die Gerichte hierzulande stets mit gutem Grund widersetzt.

\subsubsection{Adressatenkreis des Retweets}

Der Beschuldigte hat den Tweet von "NewsMän" an seine eigenen Follower weitergeleitet. Dass damals rund 1500 Twitterer Follower des Beschuldigten waren, verleitet dazu, die Reichweite des Retweets zu überschätzen. Die wenigsten Twitterer schauen systematisch alles an, was sich seit dem letzten Blick auf ihren Account getan hat. Die meisten werfen 
nur einen Blick auf die neuesten Meldungen auf ihrem Account, ohne zu den älteren hinunterzuscrollen. Wer vielen Personen folgt, muss seinen Account genau im richtigen Moment anschauen, um die Meldung des Beschuldigten überhaupt wahrzunehmen. Auch sind längst nicht alle, die sich irgendwann einmal bei Twitter registriert und die Tweets des Beschuldigten verfolgt haben, aktive Nutzer. Es ist gut möglich, dass nur eine Hand voll oder nur ein paar Dutzend Follower des Beschuldigten den fraglichen Retweet wahrgenommen haben. Allerdings dürften diese sich nicht gross von den restlichen Followern unterscheiden. Es lässt sich höchstens sagen, dass jene Twitterer, die den Retweet tatsächlich wahrgenommen haben, im Zweifel eher zu den interessierteren und zu jenen gehören, die häufig auf ihren TwitterAccount schauen.

Der Beschuldigte hatte damals bereits weit mehr Follower, als durch Familie, Freunde und Bekannte zu erklären sind. Die meisten dürften Leserinnen und Leser sein, die seine Arbeit als Journalist schätzen, ohne ihn persönlich zu kennen. Solche Follower haben ein überdurchschnittliches Interesse am Zeitgeschehen. Eine gewisse Überschneidung dürfte der Kreis der Follower des Beschuldigten auch mit dem Kreis der Leserinnen und Leser der WochenZeitung haben. Dort publiziert der Beschuldigte am meisten, so dass die meisten Follower beim Lesen der WoZ begonnen haben, sich für seine Arbeit zu interessieren, und dann begonnen haben, ihm auf Twitter zu folgen. Damit ist noch immer recht wenig über den Kreis der Follower des Beschuldigten bekannt. Es dürfte sich mehrheitlich um gut ausgebildete, überdurchschnittlich am Zeitgeschehen interessierte und politisch eher links stehende Leserinnen und Leser handeln.

\subsubsection{Hermann "Dölf" Lei in den Augen der Follower des Be- schuldigten}

Wer von der ganzen Angelegenheit um die Hitler-Domain noch nie etwas gehört oder alles bereits wieder vergessen hat, für den ist die Bezeichnung "Hermann "Dölf" Lei" unverständlich. Die einzige Persönlichkeit, die in den Medien regelmässig unter der Bezeichnung "Dölf" erscheint, ist alt Bundesrat Adolf Ogi, der mit dieser Sache überhaupt nichts zu tun hat.

Wer die Fakten rund um die HitlerDomain ganz genau vor Augen hat, der wird in der Bezeichnung "Dölf" lediglich eine Anspielung auf die vom Beschuldigten veröffentlichte Angelegenheit erblicken. Die Bezeichnung hätte dann etwa die Bedeutung "Hermann Lei, der mit der Geschichte um adolf-hitler.ch". Wer vor Augen hat, dass die Verbindung des Privatklägers zur Domain adolf-hitler.ch weit loser ist, als der erste Anschein vermuten lässt und dass es sich dabei nicht um eine Propaganda-Seite gehandelt hat, der wird in der Bezeichnung "Dölf" nicht den Vorwurf erblicken, der Privatkläger sei ein verkappter Neonazi.

Diese beiden Extreme, überhaupt kein Vorwissen oder alle Fakten exakt vor Augen, dürften jedoch beide nicht das Vorwissen des durchschnittlichen Followers des Beschuldigten wiedergeben. Die meisten, die sich für die Arbeit des Beschuldigten interessieren, dürften die Geschichte um adolf-hitler.ch mitbekommen haben. Der Artikel lag aller- 
dings bereits einen Monat zurück. Auch im Kopf von gebildeten Menschen mit regem Interesse an Politik verdrängen neuere Ereignisse rasch, was vor einem Monat aktuell war. Zudem lesen die wenigsten Menschen alle Artikel einer Zeitung, die sie abonniert haben vom Anfang bis zum Ende. Aus diesem Grund kann sogar ein missverständlicher Titel rechtswidrig sein, selbst wenn man bei der Lektüre des ganzen Artikels ein korrektes Bild erhält (vgl. BGE 137 IV 313, E. 2.1.3., S. 315f. und die dort zitierten Entscheide). Das Vorwissen des Durchschnittslesers dürfte sich deshalb darauf beschränken, dass "irgendetwas war mit dem Privatkläger und adolf-hitler.ch", ohne ganz genau im Gedächtnis abrufen zu können, worin die Verbindung zwischen dem Privatkläger und adolfhitler.ch genau bestand. Der Beschuldigte kommentierte die Fakten sinngemäss so, dass sich kein Nachweis dafür erbringen lasse, der Privatkläger sei ein Anhänger oder Verharmloser des Nationalsozialismus, die ganze Geschichte werfe aber viele offene Fragen auf, zu denen sich der Privatkläger bedeckt halte. Wer diesen Grundtenor des Artikels noch vor Augen hat, nicht aber die detaillierte Herleitung dieser Einschätzung, der ist durchaus geneigt, "Hermann "Dölf" Lei" als "Hermann Lei, der verkappte Neonazi" zu lesen. Dies erst recht, da der Kreis der Follower des Beschuldigten im Durchschnitt einem Politiker am rechten Rand der SVP wenig Wohlwollen entgegenbringen dürfte.

Es ist nochmals zu betonen, dass eine detaillierte und in den Fakten korrekte Darstellung der Verbindung des Privatklägers zu adolf-hitler.ch zulässig war. Die Verkürzung dieser Diskussion zum
Namenszusatz "Dölf" einen Monat später, als nicht mehr alle Fakten in allen Köpfen präsent waren, verletzte jedoch die Persönlichkeit des Privatklägers. Im Kontext des einen Monat zuvor erschienen Artikels des Beschuldigten ist der Zusatz als "der verkappte Neonazi" zu deuten, nicht bloss als "der mit der Hitler-Domain".

\subsection{Rechtsfolgen der Persönlich- keitsverletzung}

\subsubsection{Reaktionsmöglichkeiten des Gerichts}

Als Folge einer Persönlichkeitsverletzung kann das Gericht jeden, der daran mitgewirkt hat, verpflichten, eine Berichtigung oder das Urteil zu veröffentlichen (Art. 28a Abs. 2 ZGB). Das Gericht kann ferner die Widerrechtlichkeit einer Persönlichkeitsverletzung feststellen (Art. 28a Abs. 1 Ziff. 3 ZGB). Diese Ansprüche bestehen unabhängig vom Verschulden und unabhängig von der Schwere der Persönlichkeitsverletzung.

Sofern die Schwere der Persönlichkeitsverletzung es rechtfertigt, kann das Gericht auch eine Geldsumme als Genugtuung zusprechen oder auf eine andere Art der Genugtuung erkennen (Art. 49 Abs. 1 und Abs. 2 OR). Auch eine Richtigstellung oder eine Veröffentlichung des Urteils kommt als andere Form der Genugtuung in Frage. Der Anspruch auf Genugtuung setzt neben der Schwere der Verletzung Verschulden voraus (zum Ganzen: BGE 131 III 26, E. 12.1 und E. 12.2, S. 29ff.).

Der Privatkläger hat auf Frage des Gerichts erklärt, er könne sich auch eine andere Form der Genugtuung als Geld 
vorstellen. Das Gericht könnte sogar von Amtes wegen auf eine andere Form der Genugtuung erkennen (ROLAND BREHM, Berner Kommentar, 4. Auflage, 2013, N 98 zu Art. 49 OR). Der Anwendungsbereich von Art. 49 Abs. 2 OR ist beschränkt, gerade bei Ehrverletzungen kann aber eine immaterielle Form der Genugtuung angemessener sein als Geld. Die Wahl zwischen den verschiedenen Formen der Genugtuung ist ein Ermessensentscheid, der zu begründen ist (BGE 131 III 26, E. 12.2.2, S. 31).

\subsubsection{Voraussetzungen der Genug- tuung (Art. 49 Abs. 1 und Abs. 2 OR)}

Der implizit mit dem Retweet erhobene Vorwurf, der Privatkläger sei ein Anhänger oder Verharmloser des Nationalsozialismus, verletzt dessen Persönlichkeit schwer genug, um eine Genugtuung zu rechtfertigen. Den Beschuldigten trifft ein Verschulden, zumindest in der Form der Fahrlässigkeit. Er wusste wie kein zweiter, was seine Recherchen ergeben hatten und was nicht. Er hätte bedenken müssen, wie die Verkürzung seiner rechtmässigen Berichterstattung zum Übernamen "Dölf" auch noch verstanden werden kann, auch wenn er selbst darin nur einen Hinweis auf seinen Artikel sehen will. Bezüglich der Schwere der Persönlichkeitsverletzung ist immerhin auch festzuhalten, dass die Reichweite seines Retweets beschränkt gewesen sein dürfte.

\subsubsection{Geldsumme oder andere Form der Genugtuung}

Der Privatkläger war Verwaltungsrat und später nur noch Domizilgeber der X. AG, welche aus kommerziellen Gründen adolf-hitler.ch aufschaltete, aber keine Propagandaseite betrieb. Die Berichterstattung darüber war dem Privatkläger gegenüber nicht sehr wohlwollend, aber rechtmässig. Die Pressefreiheit schützt auch ein gewisses Mass an Zuspitzung, Übertreibung und Ungenauigkeit. Als aktiver Politiker hatte es der Privatkläger hinzunehmen, dass ein Journalist seine Geschäftstätigkeit durchleuchtet. Der Ärger, der dadurch entsteht, dass der Privatkläger seinen Namen immer wieder im Zusammenhang mit der HitlerDomain in der Zeitung lesen musste, ist nicht Folge des rechtswidrigen Retweets. Darauf kann es bei der Festsetzung einer Genugtuung nicht ankommen.

Den ursprünglichen Tweet von "NewsMän" und den Retweet des Beschuldigten hat der Privatkläger fast zehn Monate lang überhaupt nicht wahrgenommen und auch nicht darunter gelitten. Er stiess nur darauf, weil er mit einer speziellen Suchmaschine die alten Tweets des Beschuldigten durchstöbert hat. Seine spontane Reaktion auf seinen Fund war in erster Linie Freude darüber, eine Äusserung gefunden zu haben, die zu weit geht und gute Prozesschancen bietet. Als er auf den Retweet stiess, schrieb er einem Bekannten, der sich mit Twitter besser auskannte: "Sali X. Ich glaub jetzt habe ich Hanimann am Wickel. (...)". Unter dem rechtswidrigen Retweet hatte der Privatkläger nicht $\mathrm{zu}$ leiden. Hinzu kommt, dass hier eine Äusserung, die zu weit geht, in einer an sich legitimen politischen Debatte gefallen ist. Auch bei der Auslegung des Zivilrechts ist die Freiheit der Meinungsäusserung mit zu bedenken. Mit der Beteiligung an politischen Debatten auf Twitter sollten finanzielle Risiken nur zurückhaltend verknüpft 
werden. Geld als Genugtuung wäre eher angemessen bei Cybermobbing ohne politischen Kontext.

Der Privatkläger ist nicht auf Geld als Trost und Ausgleich für seinen Ärger angewiesen, der nicht Folge des Retweets ist. Weit besser gedient ist ihm mit einer Korrektur des falschen Eindrucks, den der Übername "Dölf" geschaffen hat (vgl. BGE 131 III 26, E. 12.2.2, S. 31). Der Beschuldigte ist deshalb zur Wiedergutmachung der Persönlichkeitsverletzung zu verpflichten, dieses Urteil auf Twitter bekannt zu machen. So lässt sich der Adressatenkreis des ursprünglichen Retweets am Besten erreichen. Mit dieser für den Privatkläger wirksamen und für den Beschuldigten kostengünstigen Art der Genugtuung lassen sich die legitimen Anliegen, den guten Ruf zu schützen und Debatten im Internet nicht an unüberschaubare Risiken zu knüpfen, am ehesten in Einklang bringen.

Eine Kurznachricht auf Twitter umfasst höchstens 140 Zeichen. Das lässt keinen Raum für eine differenzierte Darlegung der Überlegungen des Gerichts. Der Tweet muss deshalb einen Hinweis auf die Urteilsnummer enthalten. Damit finden Interessierte die Berichterstattung in den Medien und können sich selbst ein Bild machen. Auch der Freispruch ist zu erwähnen. Wer sich für die Angelegenheit interessiert, wird vielleicht andernorts eine Nachricht vom Freispruch ohne Bericht über die zivilrechtliche Regelung finden und denken, das Erkenntnis betreffend Persönlichkeitsverletzung sei überholt. Diese Überlegungen führen zur Verpflichtung des Beschuldigten, auf seinem Twitter-Account folgende Meldung zu veröffentlichen: "Bezirksgericht
Zürich: Retweet von "Hermann <Dölf> Lei" nicht strafbar, aber persönlichkeitsverletzend. Urteil Nr. GG150250-L."

\section{Kosten- und Entschädigungs- folgen}

Wird die beschuldigte Person freigesprochen, so können ihr die Verfahrenskosten ganz oder teilweise auferlegt werden, wenn sie rechtswidrig und schuldhaft die Einleitung des Verfahrens bewirkt hat (Art. 426 Abs. 2 StPO). Eine Kostenpflicht für unnötige Verfahren ist jedoch auch bei schuldhafter Verursachung ausgeschlossen (Art. 426 Abs. 3 lit. a StPO).

Der Beschuldigte hat die Persönlichkeit des Privatklägers durch seinen Retweet verletzt und damit rechtswidrig gehandelt. Ohne den Retweet hätte es das Strafverfahren nicht gegeben. Aufgrund von Art. 28 StGB war der Retweet jedoch kein zureichender Grund für ein Strafverfahren. Zwischen dem rechtswidrigen Retweet des Beschuldigten und dem Strafverfahren besteht ein natürlicher, aber kein adäquater Kausalzusammenhang, so dass der Beschuldigte nicht kostenpflichtig wird. Die Kosten, einschliesslich jener für das obergerichtliche Beschwerdeverfahren, sind auf die Gerichtskasse zu nehmen. Dem entsprechend ist der Beschuldigte aus der Gerichtskasse $\mathrm{zu}$ entschädigen (Art. 429 Abs. 1 lit. a StPO). Da dem Beschuldigten keine Kosten auferlegt werden können, kann er auch nicht verurteilt werden, den Privatkläger für seinen Aufwand zu entschädigen (Art. 433 Abs. 1 lit. b StPO). Es muss mit den regulären Kosten und Entschädigungsfolgen eines Freispruchs sein Bewenden haben. 